UNIVERSIDAD NACIONAL DE LA PLATA

Facultad de Ciencias Médicas

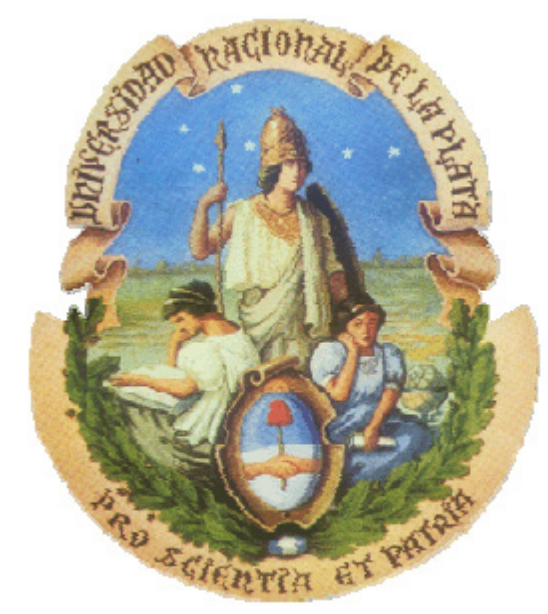

\title{
RESPUESTA HORMONAL FRENTE A LA EXPOSICIÓN AL ESTRÉS EN ESTUDIANTES CON Y SIN HISTORIA FAMILIAR DE ABUSO YIO DEPENDENCIA DE ALCOHOL
}

Tesis Doctoral

2015

Tesista: Medico Esteban Javier Dávila Peralta

Director: Prof. Dr. Manuel Suarez Richards

Jurado: Prof. Dr. Ricardo Angelino, Prof. Dr. Néstor Koldobsky, Prof. Dr. Jorge Folino Suplentes: Prof. Dr. José Luis Carreras, Prof. Dr. Osvaldo Fournes, Prof. Dr. Horacio Curcio 


\section{AUTORIDADES DE LA UNLP \\ Presidente: Lic. Raúl Aníbal PERDOMO \\ Vicepresidencia Área Académica: Prof. Ana María BARLETTA \\ Secretaría General: Dr. Leonardo GONZALEZ \\ AUTORIDADES DE LA FACULTAD DE CIENCIAS MÉDICAS}

Decano: Prof. Dra. Ana Lía ERRECALDE

Vicedecano: Prof. Dr. Eduardo ESCUDERO

Secretaria de Asuntos Académicos: Prof.

Dr. Julio Cesar HIJANO

Secretaria de Asuntos Estudiantiles: Prof.

Dra. María Marta DE LUCA

Secretaria de Extensión Universitaria:

Prof. Dra. Graciela S. ETCHEGOYEN

Secretario Docente Asistencial: Prof. Dr.

Guillermo Daniel PRAT

Secretario de Ciencia y Técnica: Prof. Dr.

Gustavo Juan RINALDI

Secretario Económico Financiero: Cdor.

Rubén GALLE

SECRETARIO del Departamento de

Postgrado: Prof. David COSTI

Directora de la Escuela Universitaria de

Recursos Humanos del Equipo de Salud:

Prof. Dra. María Gabriela BISCEGLIA

Director del Hospital Universitario

Integrado (HUI) y Director Ejecutivo del

Hospital Universitario de Alta Complejidad

(HUDAC): Prof. Dr. Guillermo MARTINEZ

Asesor de Gestión: Dr. Felipe

CAMPOAMOR

Secretaria de Supervisión Administrativa:

Sra. Norma FORTUNATO de

CARRADORI

Secretaria Administrativa: Sra. Elsa Lidia ANTONINI

\section{CONSEJO SUPERIOR}

Claustro Profesores: TITULAR:

RAIMONDI, Jorge Clemente.

SUPLENTE: LUPI, Gabriel Horacio

Claustro Graduados: TITULAR: SEMPER, Raúl Alfredo, SUPLENTE: VILELA, Pablo Claustro Estudiantil: TITULAR: ALBERTI, Ignacio, SUPLENTE: BONIFACIO, Yesica CONSEJO DIRECTIVO

Claustro Profesores: TITULARES:

COBOS Marisa Margarita, CARRERA José Luis, ESCUDERO Eduardo Daniel, OCCHIUZZI Juan Carlos, SUAREZ Isabel Beatriz, SIMONETTO Raúl Carlos, GOUFFIER Víctor Bernardo.

SUPLENTES: DRUT Ricardo, SALAS

Margarita Ana, GUADIX Ernesto Martin, DELUCCHI Gustavo Alfredo, GIRARDELLI Ana María, COSCARELLI Leonardo Carlos Oscar, CASTILLO Jorge Luis.

Claustro Jefes de Trabajos Prácticos

TITULAR: EMMERICH Juan. SUPLENTE: MORANTE Marcelo.

Claustro Ayudantes Diplomados:

TITULAR: GUITERREZ Héctor.

SUPLENTE: BASSO Gabriel Hugo.

Claustro Graduados: TITULAR: Morante, Mariela. SUPLENTE: Llarull, Osvaldo 


\section{ÍNDICE DE CONTENDIDO}

Pág.

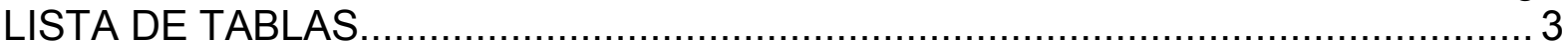

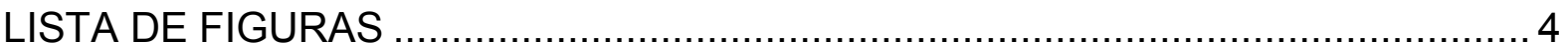

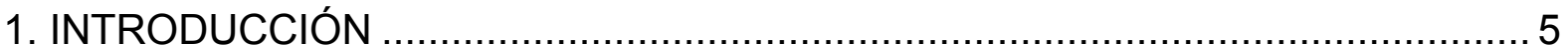

1.1 El estrés: Introducción histórica y concepto ………............................... 5

1.2 Respuesta fisiológica del estrés....................................................... 7

1.3 El consumo de alcohol como problema para la salud ............................ 14

1.4 Antecedente familiar de alcoholismo y respuesta frente al estrés ............ 23

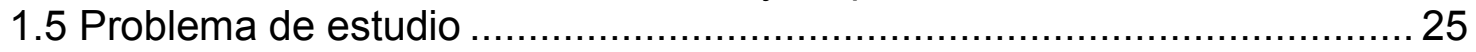

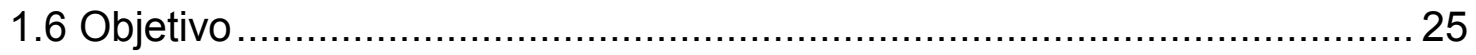

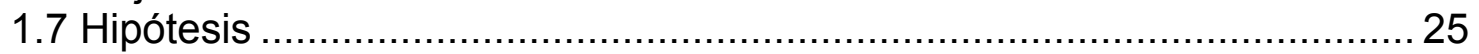

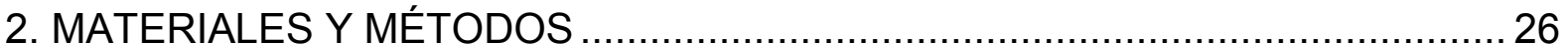

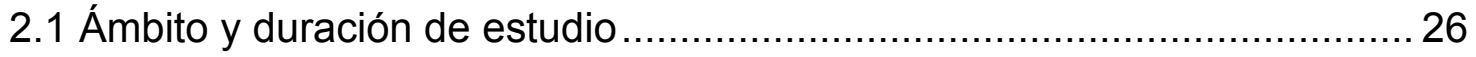

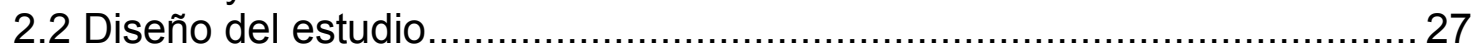

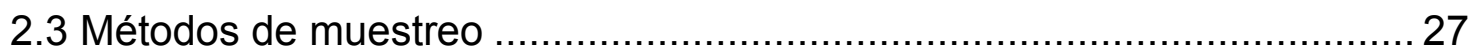

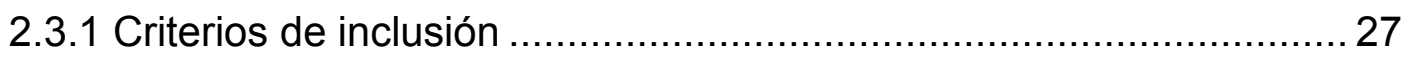

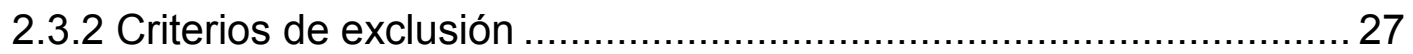

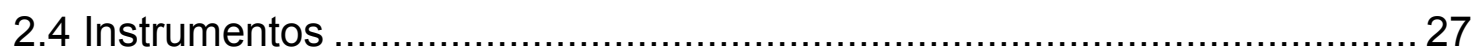

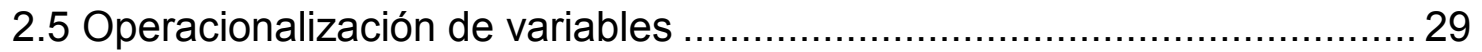

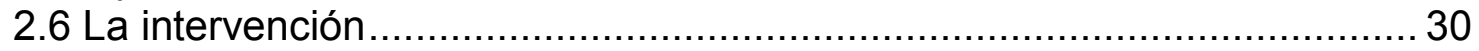

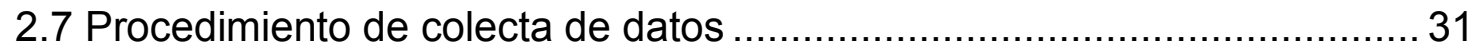

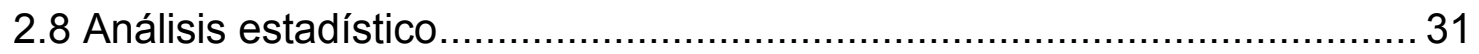

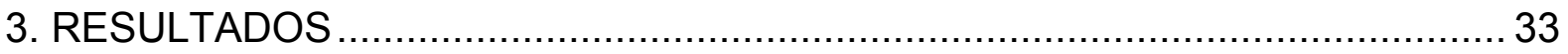

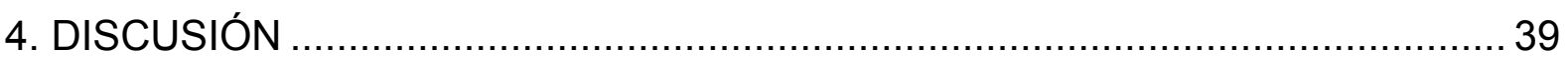

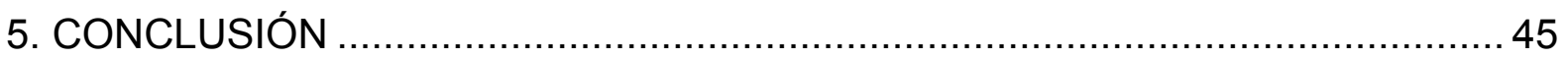

6. FORTALEZAS Y DEBILIDADES DEL ESTUDIO ............................................ 46

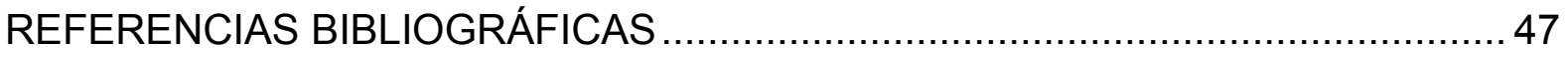

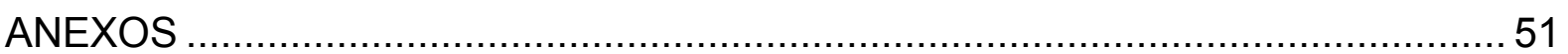

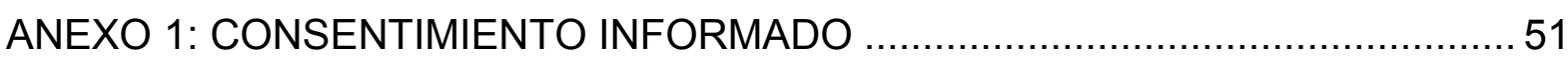

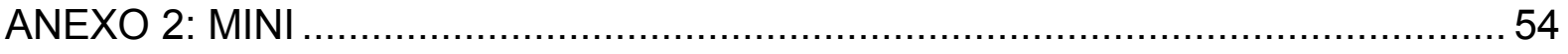


ANEXO 3: FTQ (FAMILY TREE QUESTIONNAIRE)

ANEXO 4: T.S.S.T. (TRIER SOCIAL STRESS TEST)

58

ANEXO 5: TABLAS DE RESULTADOS DEL SPSS . 633 


\section{LISTA DE TABLAS}

Pág.

1. Comparación cantidad de alcohol etílico en el organismo y los cuadros que provoca. 19

2. Características basales de los participantes del estudio ................................... 36

3. Medias y desvíos según antecedentes de alcoholismo y la variable tiempo.........38 


\section{LISTA DE FIGURAS}

Pág.

1. Producción de hormonas por el Sistema Nervioso Vegetativo y el eje Hipotálamo-Hipofiso-Suprarrenal. 13

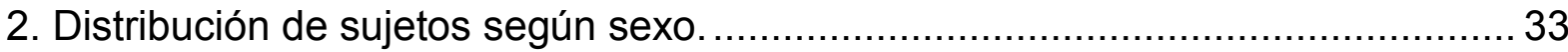

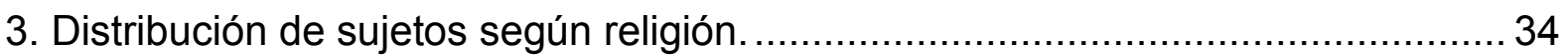

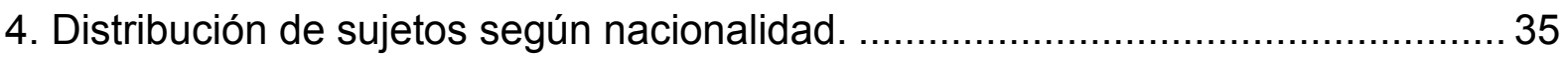

5. Medias en función de grupos CON y SIN antecedentes de alcoholismo y de la variable tiempo. 


\section{INTRODUCCIÓN}

\subsection{El estrés: Introducción histórica y concepto}

El tema del estrés es complejo y problemático tanto en su delimitación conceptual como en la metodología de su estudio. Aunque el término ya empezó a utilizarse en el siglo XV con el significado de presión o tensión física, no fue hasta comienzos del siglo XX cuando se introdujo en medicina.

En 1929 Walter Cannon fue el primero en establecer el vínculo directo entre la actividad emocional y la función del Sistema Nervioso Simpático al escribir la "Teoría emergente de la emoción" (1). Sería la ruptura de la homeostasis que el organismo debía de restablecer para que no desembocara en enfermedad alguna, y utilizando el termino estrés "para designar las influencias del medio que exigen un esfuerzo inhabitual de los mecanismos homeostáticos encargados de mantener la constancia del medio interno".

Algunos años más tarde, en 1936 el termino estrés fue introducido por el médico fisiólogo Hans Selye de Montreal, originalmente se refirió a las reacciones inespecíficas del organismo ante estímulos tanto psíquicos como físicos, involucrando procesos normales de adaptación (eustress) así como anormales (distres). Los estudios originales de Selye se hicieron a partir del "síndrome general de adaptación" descrito como la respuesta general del organismo a estímulos "estresantes" o amenazantes y definió al estrés como "la respuesta inespecífica del organismo ante toda demanda hecha sobre él".

Selye describió tres formas clásicas de la respuesta orgánica:

1. fase de alarma (primitiva respuesta de preparación para la lucha o la huida)

2. fase de resistencia

3. fase de agotamiento neurovegetativo o de claudicación o cansancio (2).

Mason en 1968 fue el primero que señalo a la actividad emocional como primer mediador y agente sobre el hipotálamo, responsable a su vez de la actividad endocrina propia de la reacción biológica de estrés (3). Por lo tanto, según Mason las situaciones nocivas o desagradables provocan una reacción biológica al igual 
que la reacción de lucha o huida de Cannon. Mason estableció así su teoría neuroendocrina sobre el estrés, rebatiendo la supuesta inespecificidad de respuesta al estrés postulada por Selye.

En 1967 Rahe y Colmes decidieron definir el estrés como un suceso que supone un cambio mayor en la pauta de vida habitual, abarcando muchas circunstancias vitales (bodas, nacimientos etc.) que consideraron como favorecedoras de muchas enfermedades (4). Esta visión como "ajuste social" que define al estrés como la intensidad y tiempo necesario para adaptarse y adecuar la conducta a los eventos de la vida que en un momento determinado aparecen en la existencia, hizo posible la creación del concepto de "estresor".

Seligman en 1975 fue con su teoría de la indefensión aprendida el que inició el desarrollo de los modelo cognitivos de estrés, el cual postula que el individuo sometido a experiencias traumáticas incontrolables en sus primeros aprendizajes llega a percibir a nivel cognitivo la ineficacia de sus respuestas frente a los acontecimientos que posteriormente se le presenten y le recuerden anteriores experiencias (5).

Lazarus y Folkman (1966) definieron el estrés "como una particular relación entre la persona y el entorno que es evaluado por ésta como gravoso o que excede sus recursos y que arriesga su bienestar o salud" (6). Es decir que la persona interpreta al entorno como amenazante, difícil, que supera su capacidad para afrontarlo generando un estado de tensión y como consecuencia atenta contra su bienestar.

En 1971 Levi definió al estrés como una estimulación producida por cognición amenazadora que incrementa la activación de un organismo más rápidamente que su capacidad de adaptación para atenuarla (7).

En 1978 Abramson incorpora la teoría de la "atribución" que refiere que al desarrollo de este patrón de indefensión -postulado por Seligman en 1975contribuye el hecho de que el sujeto atribuye poco control de las consecuencias a déficit personales, internos globales y estables, lo que desencadena una reacción emocional (8).

Por otra parte y desde un punto de vista axiológico, se encuentra la duda de si el estrés es algo bueno o no. Al decir axiológico, está en referencia a la naturaleza de los valores y los juicios valorativos. Aquellos valores negativos como positivos, 
analizando sus primeros principios que son aquellos que permitirán determinar la valía o no de algo o alguien, para luego formular los fundamentos del juicio, tanto en el caso de ser positivo como negativo. Para unos es sinónimo de sobresalto, para otros de malestar y para muchos como exponente de tensión, conceptuándose como algo malo que antecede a muchas enfermedades.

Lader afirmó que el concepto de estrés es más filosófico que científico al implicar valores y modelos de vida en relación con la cultura (9). Si consideramos que el estrés es una reacción a una serie de eventos que se consideran peligrosos, las repercusiones que tiene este sobre el organismo son necesarias para lograr un nuevo estado de adaptación y por lo tanto buenas, siempre que no se prolongue durante mucho tiempo, o sea tan intensa que desborde la capacidad del organismo de responder a los factores que lo causaron.

Como el estrés es una vivencia común, incluso el uso del término se ha extendido socialmente, debemos valorar el alcance individual del mismo y su duración e intensidad con el objetivo de que no constituya un factor favorecedor de enfermedad o deteriore los rendimientos y capacidades de las personas sometidas a él (10).

\subsection{Respuesta fisiológica del estrés}

La respuesta fisiológica del estrés es la reacción que se produce en el organismo ante los estímulos estresores.

Los estresores o situaciones desencadenantes del estrés se definen como cualquier estimulo externo o interno (físico, químico, acústico, somático o sociocultural) que de forma directa o indirecta desestabilizan el equilibrio dinámico del individuo (11).

Existen ocho grandes categorías de estresores: situaciones que fuerzan a procesar la información rápidamente, estímulos ambientales dañinos, percepciones de amenaza, alteraciones de funciones fisiológicas (enfermedad, drogas), aislamientos y confinamiento, bloqueo de nuestros intereses, presión grupal y por ultimo frustración (12).

Refiriéndose a los cambios psicosociales que pueden acontecer por estos estresores, Lazarus (13) realizo una clasificación en cuatro tipos de desencadenantes del estrés: 
1. Estresores únicos: hacen referencia a catástrofes y cambios dramáticos en las condiciones del entorno de las personas. Afectan a un gran número de ellas.

Dentro de esta categoría se encontrarían:
a. Situaciones bélicas
b. Terrorismo
c. Víctimas de violencia
d. Enfermedades terminales
e. Situaciones de cirugía mayor
f. Migración y desarraigo
g. Catástrofes naturales
h. Sucesos altamente traumáticos (divorcio, perdidas familiares, etc.).

Tienen en común que el efecto traumático físico y/o psicológico se mantiene de forma prolongada. Estos estresores son los responsables de las reacciones de estrés agudo y pueden dar lugar al trastorno de estrés postraumático.

2. Estresores múltiples: se trata de acontecimientos que pueden hallarse fuera del control de una persona como ser:

a. Muerte de un ser querido

b. Situación de amenaza a la propia vida

c. Enfermedad incapacitante

d. Pérdida del empleo u otro tipo de acontecimientos que están fuertemente influidos por la propia persona (divorcio, tener un hijo, someterse a un examen importante, etc.)

Estos estresores múltiples son los responsables del estrés crónico.

Existe una serie de áreas de la vida de las personas que suponen alteraciones, con una trascendencia vital, que son altamente significativas y por tanto fuentes desencadenantes de estrés. Estos cambios serian:
a. La vida en pareja, matrimonial y extramatrimonial
b. Paternidad (dificultades paterno-filiales, enfermedad de un hijo)
c. Relaciones interpersonales (disputas, relaciones difíciles con un jefe o vecino)
d. Ámbito laboral (paro, jubilación, problemas académicos)
e. Situaciones ambientales (cambio de residencia, inmigración) 
f. Ámbito económico (manejo inadecuado de finanzas, cambio de estatus económico)

g. Cuestiones legales (ser detenido, encarcelado, pleitos, juicios)

h. Proceso evolutivo de las personas (pubertad, menopausia, crisis de los cuarenta)

i. Lesiones o enfermedades somáticas

j. Otros tipos de estrés psicosociales (sufrir persecución, embarazo no deseado)

k. Niños o adolescentes: malas relaciones con padres u hostilidad abierta, trastornos somáticos o mentales en miembros de la familia, intrusismo paterno-filial, insuficiente control paterno, situación familiar anómala.

El padecimiento de varios de estos estresores tiene un efecto sumatorio, pudiendo llegar a tener el mismo impacto que un estresor único. Los estresores múltiples actúan cambiando los patrones de comportamiento automatizados y manteniendo respuestas de estrés crónicamente hasta que se produce una acomodación a las nuevas condiciones.

3. Estresores cotidianos: suponen pequeñas situaciones que pueden perturbarnos $\mathrm{o}$ irritarnos en un momento dado, se trata de alteraciones de las rutinas diarias como sufrir un atasco o quedarse sin dinero suelto. Hay que diferenciar dos tipos de estresores cotidianos:

a. Las contrariedades que causan malestar emocional o demandas irritantes que pueden ser problemas prácticos (perder algo, mancharse un traje, etc.), sucesos fortuitos como fenómenos meteorológicos o rotura de un objeto

b. Problemas sociales (decepción por parte de un ser querido o tener problemas familiares).

Los estresores cotidianos son responsable de desencadenar procesos de estrés en un porcentaje estadísticamente mayor que el producido por los estresores únicos y múltiples.

4. Estresores biogénicos: actúan directamente sobre el organismo causando o desencadenando la respuesta de estrés. Estos estímulos evitan el mecanismo de valoración cognitiva. 
Ante una situación de estrés, el organismo tiene una serie de reacciones fisiológicas que suponen la activación del eje Hipotálamo-Hipofisario-Adrenal (HHA) y del sistema nervioso vegetativo. (Ver figura 1).

El eje HHA está compuesto por el hipotálamo que es una estructura nerviosa situada en la base del cerebro que actúa de enlace entre el sistema endocrino y el sistema nervioso; la hipófisis, una glándula situada asimismo en la base del cerebro; y las glándulas suprarrenales que se encuentran sobre el polo superior de cada uno de los riñones, que están compuestas por corteza y medula. La medula suprarrenal ocupa el $20 \%$ central de la glándula, se relaciona desde el punto de vista funcional con el sistema nervioso simpático, secreta las hormonas adrenalina y noradrenalina como respuesta a la estimulación simpática. La corteza suprarrenal secreta mineralocorticoides (aldosterona, desoxicorticosterona, corticosterona, 9 alfa fluorocortisol, cortisol y cortisona) y glucocorticoides (cortisol, corticosterona, cortisona, prednisona, metilprednisona y dexametasona).

El sistema nervioso vegetativo (SNV) está conformado por un conjunto de estructuras nerviosas que se encargan de regular el funcionamiento de los órganos internos y controla algunas de sus funciones de manera involuntaria e inconsciente.

Ambos sistemas, el eje HHA y el SNV, producen la liberación de hormonas, sustancias elaboradas en las glándulas que transportadas a través de la sangre excitan, inhiben o regulan la actividad de los órganos.

El eje HHA, se activa con las agresiones físicas como con las psíquicas y al activarse el hipotálamo segrega la hormona CRF (factor liberador de corticotropina) que actúa sobre la hipófisis y provoca la secreción de la hormona ACTH (adenocorticotropa). Esta secreción incide sobre la corteza de las glándulas suprarrenales dando lugar a la producción de corticoides que pasan al torrente circulatorio y producen múltiples incidencias orgánicas como se verá más adelante. Los corticoides que se liberan debido a la ACTH son: los glucocorticoides, el más importante es el cortisol. Los glucocorticoides tienen acciones y repercusiones en todo el organismo. Podemos resumirlas en: metabolismo de carbohidratos y proteínas, conservación del equilibrio de lípidos y electrolitos, preservación de la función normal de los sistemas cardiovascular e inmunitario, renal, músculo estriado y regulación del sistema psiconeuroinmunoendocrino en su totalidad $(14,15)$. 
La exposición al estrés afecta no solo a la función adenocorticotropica, sino también a otras hormonas como las tiroideas, las gonadotrofinas, la prolactina y los péptidos opioides (16).

Entonces, el estrés intenso se acompaña de la liberación a la sangre de diversas hormonas entre las que se encuentran el cortisol, la adrenalina y noradrenalina, la vasopresina, la oxitocina y los opioides endógenos. Estas sustancias ayudan al organismo a movilizar la energía requerida para afrontar una situación de alarma o emergencia, desde la simple liberación de glucosa a la sangre hasta una activación del sistema inmune (17). En un organismo normal el estrés produce una rápida y pronunciada elevación en los niveles sanguíneos de estas hormonas los cuales retornan con celeridad a niveles normales después de finalizada la situación estresante (18).

El cortisol liberado en niveles adecuados y durante poco tiempo, recupera la energía utilizada durante la fase de lucha o huida (regulando el metabolismo de hidratos de carbono, lípidos y proteínas), ayuda al sistema inmune y facilita la neuroplasticidad; esta última incluye la remodelación sináptica, la extensión de neuritas, la sinaptogénesis, la neurogénesis y la potenciación a largo plazo, y se relaciona con la reparación de sinapsis lesionadas o con desgaste fisiológico, con el aprendizaje y con la memoria. (19) Esto genera la reacción denominada alostasis, definida como la respuesta fisiológica al estrés con la cual las funciones corporales se adaptan en respuesta a un cambio del entorno y ayuda a enfrentarnos a las situaciones estresantes de la vida cotidiana (20).

Los glucocorticoides y las catecolaminas (adrenalina y noradrenalina) parecen modular sus efectos de forma recíproca de tal forma que en situaciones de estrés agudo, el cortisol ayuda a regular la liberación de catecolaminas mediante un mecanismo de "retroalimentación" negativa que abarca al hipocampo, hipotálamo e hipófisis (21).

El sistema nervioso vegetativo mantiene la homeostasis del organismo. La activación simpática supone la secreción de catecolaminas como la adrenalina, segregada por parte de la medula suprarrenal, especialmente en casos de estrés psíquico y de ansiedad $\mathrm{Y}$ la noradrenalina segregada por las terminaciones nerviosas simpáticas aumentando su concentración principalmente en el estrés de tipo físico, en situaciones de alto riesgo o de agresividad. Estas hormonas son las 
encargadas de poner el organismo en estado de alerta preparándolo para luchar o huir. Son las que permiten enlazar el fenómeno de estrés con los fenómenos psicofisiológicos de la emoción. Ambas intervienen en los siguientes procesos:
a. Dilatación de pupilas
b. Dilatación bronquial
c. Movilización de los ácidos grasos, pudiendo dar lugar a un incremento de lípidos en sangre (posiblemente vinculado a la arteriosclerosis)
d. Procoagulante
e. Incremento del rendimiento cardiaco que provoca hipertensión arterial
f. Vasodilatación arterial a nivel muscular y vasoconstricción a nivel cutáneo
g. Reducción de los niveles de estrógenos y testosterona
h. Inhibición de la secreción de prolactina que influye sobre la glándula mamaria
i. Incremento de la producción de tiroxina que favorece el metabolismo energético, la síntesis de proteínas, etc.
Vemos pues que ante una situación de estrés existe un compromiso de todo el organismo (22). 


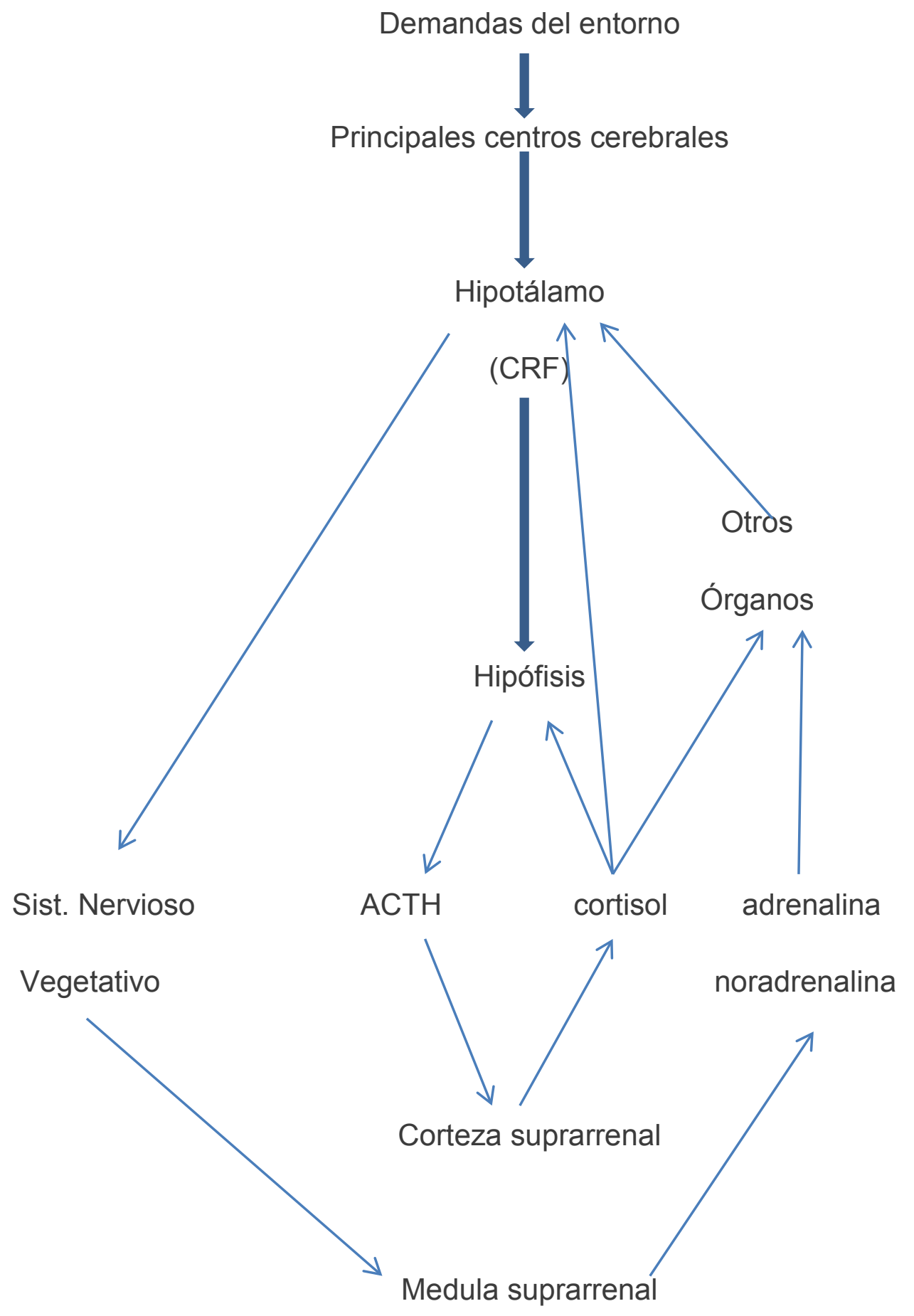

Figura 1. Producción de hormonas por el Sistema Nervioso Vegetativo y el eje Hipotálamo-Hipofiso-Suprarrenal. 


\subsection{El consumo de alcohol como problema para la salud}

El alcohol es una sustancia psicotropa, depresora del SNC con acción reforzadora positiva y propiedades causantes de dependencia psicofísica que presenta como síntomas más importantes la tolerancia y la abstinencia. Como dependencia se entiende un patrón desadaptativo de consumo de alcohol que conlleva un deterioro o malestar clínicamente significativo (DSM IV). La tolerancia se manifiesta como la necesidad de incrementar progresivamente la cantidad de alcohol para conseguir los cambios afectivos y conductuales que anteriormente lograba con cantidades menores, y, la abstinencia es un conjunto de síntomas y signos que aparecen cuando el sujeto interrumpe (voluntaria o involuntariamente) o reduce notablemente el consumo.

Los síntomas de abstinencia alcohólica incluyen:

a. Temblor de grandes oscilaciones en brazos, boca y lengua principalmente.

b. Náuseas y vómitos

c. Sudoración

d. Trastornos del sueño

e. Alteración del humor y nerviosismo

f. Ansiedad

g. Tristeza e irritabilidad

h. Hipertensión arterial

i. Alteración de la temperatura corporal

j. Hiperreflexia (23).

El alcohol, se ha utilizado ampliamente en muchas culturas durante siglos, para celebrar, socializar o en ceremonias religiosas. En China se encontraron jarrones, en un yacimiento del rio Amarillo, donde había restos de líquido (alrededor de 7000 AC), identificados como una bebida que mezclaba miel, arroz, uvas silvestres y frutos de espino chino (24), con propiedades del etanol. El inicio de la agricultura alrededor de 6000 AC y el posterior descubrimiento de la fermentación fue seguido de la producción de alcohol. Las bebidas alcohólicas eran "mayormente conocidas y utilizadas en nuestras regiones de América antes del contacto con la expansión imperial europea de los últimos 500 años" (25). Durante la mayor parte de los varios milenios que conforman su historia, se han producido bebidas 
alcohólicas principalmente a nivel doméstico o en comunidades pequeñas. Lo que se producía generalmente se consumía pronto y a nivel local. Se usaban en el hogar y se regalaban como signo de generosidad $u$ hospitalidad o se compartían en festivales comunitarios y dentro de círculos locales de intercambio, para celebrar la finalización de las cosechas o de algún proyecto de trabajo conjunto. La producción de alcohol presupone la existencia de un excedente agrícola; por esta razón, y por su poder de intoxicación, en muchas sociedades las bebidas alcohólicas eran consideradas como mercancías especiales. Su consumo estaba muchas veces restringido a ciertos grupos de población, a ocasiones específicas o a ceremonias religiosas.

Cuando se habla de alcohol se refiere generalmente al etanol o alcohol etílico, por ser el constituyente fundamental de las bebidas alcohólicas. Estas son de dos tipos: bebidas fermentadas: obtenidas por fermentación de un mosto abundante en azucares: sidra, vino y cerveza, su grado de alcohol puede oscilar entre 5 y 15 grados. Bebidas destiladas: se obtienen mediante un proceso artificial, destilando una bebida fermentada y aumentando su concentración de alcohol puro; como la ginebra, ron, whisky, vodka, anís, coñac, aguardiente, licores frutados y determinados aperitivos; su grado de alcohol suele oscilar entre 17 y 45 grados. No existen diferencias en el alcohol presente en las distintas bebidas, la única diferencia está en el grado de concentración de alcohol.

Contenido en gramos de alcohol (etanol 100\%) de las bebidas más usuales:

a. Vino: un vaso $(100 \mathrm{ml})$ contiene 8 gramos

b. Cerveza: $200 \mathrm{ml}$, contiene 8.8 gramos

c. Licor: una copa $(50 \mathrm{ml})$, contiene 16 gramos

d. Vermouth: $100 \mathrm{ml}$, contiene 16 gramos

e. Sidra: $100 \mathrm{ml}$, contiene 3.6 gramos

f. Whisky: $100 \mathrm{ml}$, contiene 34 gramos.

El consumo de alcohol puede describirse en términos de gramos de alcohol consumido o por el contenido alcohólico de las distintas bebidas, en forma de unidades de bebida estándar. Una bebida normal se define como: $35,4 \mathrm{cl}$ de cerveza, $177 \mathrm{ml}$ de vino o $44,5 \mathrm{ml}$ de licor destilado, las cuales contienen la misma cantidad de etanol. 
La graduación alcohólica se suele indicar en la etiqueta de la botella en \% volumétricos (ej. Vol. 27\%; vol. 42\%, etc.). En América Latina es usual, en honor a J. Gay-Lussac, "Vol." o volumen, otras veces se usa las iniciales ${ }^{\circ} \mathrm{GL}$ del citado sabio, precedidas de un superíndice. En la práctica Vol. o vol. y ${ }^{\circ} \mathrm{GL}$ significan lo mismo. A cada unidad de porcentaje de alcohol en el volumen total le corresponde un grado en la escala alcohólica. Así se habla de un vino con una graduación de $13,5^{\circ}$ cuando tiene $13,5 \mathrm{ml}$ de etanol cada $100 \mathrm{ml}$ de vino. La graduación alcohólica relativamente baja del vino y sobre todo de la cerveza se compensa por la ingestión de un volumen mayor de bebida; el tamaño de los vasos es inversamente proporcional al contenido en alcohol de la bebida.

Para conocer la cantidad de alcohol que contienen las bebidas de consumo habitual se utiliza la siguiente operación matemática: gramos de etanol puro ingerido $=\left(G^{\circ} \times \mathrm{ml} \times 0,80\right) / 100$. En la formula basta reemplazar la variable $G^{\circ}$ por la graduación alcohólica de la bebida. Donde figura "ml" debe colocarse la cantidad de bebida consumida, expresada en mililitros. El 0,80 reemplaza en la formula al peso de 1 gramo de alcohol puro que es 0,80 gr. Una vez conocida la cantidad de gramos de etanol es muy sencillo calcular su valor calórico. Por ejemplo, en media botella de vino (500 $\mathrm{ml}$ o cc) hay $48 \mathrm{gr}$ de alcohol puro $(\mathrm{Gr}=(12 \times 500 \times 0,80) / 100=48)$.

Se pueden tomar en consideración algunas cantidades de consumo para poder estimar que una persona se encuentra en un alto riesgo de ser bebedor:

A. Por diferencia de género:

Varón: más de 3 medidas estándar/día (21 medidas/semana)

Mujer: más de 2 medidas estándar/día (14 medidas/semana).

Las medidas estándar corresponden a: un vaso de vino $=120 \mathrm{ml}$; una medida de aperitivo $=30 \mathrm{ml}$; una botella de cerveza $=285 \mathrm{ml}$. (26).

B. Consumo de riesgo: es un patrón de consumo que aumenta las consecuencias adversas para la salud si el hábito del consumo persiste. La OMS lo describe como el consumo de 20 a 40 gr diarios de alcohol en mujeres y de 40 a 60 gr diarios en varones.

C. Consumo perjudicial: es el que provoca consecuencias tanto para la salud física como para la salud mental y es el consumo regular promedio de más de 40 gr de alcohol al día en mujeres y de más de 60 gr al día en varones. 
D. Consumo excesivo episódico o circunstancial: es el consumo por parte de un adulto, de por lo menos $60 \mathrm{gr}$ de alcohol en una sola ocasión; es un patrón de uso de alcohol asociado con mayores daños físicos y emocionales, incluyendo violencia, accidentes, embarazos no planificados, sexo sin protección, HIV (27).

La mayor parte del alcohol ingerido se mantiene en el organismo hasta ser metabolizado a nivel hepático en anhídrido carbónico y agua. El 1 al 5\% se elimina por el aire espirado gracias a su elevada volatilidad (las determinaciones de alcoholemia recogen el aire espirado); el 1 al $5 \%$ se elimina por orina permitiendo la determinación de alcoholuria. En el estómago, la enzima alcohol deshidrogenasa $(\mathrm{ADH})$ lo oxida a acetaldehído, cuando ingresa en bajas cantidades ("bebedor social") esto impide que ingrese en la circulación sistémica, no es tan así en la mujer ya que tiene menor cantidad de $\mathrm{ADH}$ gástrica y por ello, aun con pequeñas cantidad, tendrá mayor nivel de alcoholemia que el varón. En el hígado, el hepatocito oxida al etanol y forma acetaldehído. El hidrogeno liberado en la oxidación es transferido del sustrato al cofactor nicotinamida adenina dinucleotido (NAD) que se convierte en su forma reducida NADH y así se produce el incremento de la ratio NADH/NAD la cual será la responsable de una serie de alteraciones metabólicas. El acetaldehído formado, mayoritariamente ira hacia las mitocondrias donde se degradara en acetato por acción de la enzima aldehído deshidrogenasa (ALDH) necesitándose también de la participación de NAD. Tan solo una pequeña parte del acetaldehído formado pasa a la sangre y al atravesar la barrera hematoencefálica accede al SNC donde participara en los mecanismos biológicos de la génesis de los diferentes efectos del alcohol. Este paso se realiza con dificultad, por ello el consumo de cantidades discretas no dan lugar a presencia del mismo en el SNC, no obstante la ingesta de cantidades mayores en forma aguda o cantidades menores en un alcohólico crónico (tiene dañado el hepatocito y no vehiculiza las cantidades que debiera de acetaldehído), generara una presencia en la sangre de elevadas concentraciones de acetaldehído que permiten el paso a través de la barrera hematoencefálica, con lo que habrá presencia del mismo en el SNC. El cociente láctico/pirúvico se eleva, generando acidosis que reduce la capacidad del riñón para excretar ácido úrico y provoca secundariamente hiperuricemia. 
Como la cocaína y las anfetaminas, el consumo de alcohol provoca la liberación de endorfinas que se adhieren a receptores en los centros de recompensa cerebrales provocando la sensación de placer. Lo que hasta ahora se desconocía eran los mecanismos que subyacen a este proceso de consumo y recompensa, y porque algunas personas sienten la necesidad de seguir bebiendo y otras no. Con el uso de PET (28) se observó que el consumo de la bebida alcohólica provocaba, tanto en los bebedores como en los no bebedores, la liberación de endorfinas en dos regiones del cerebro: núcleo accumbens y la corteza orbitofrontal. Esto revela que, independientemente de cuanto se beba, el consumo de alcohol produce la liberación de endorfinas en esas dos regiones y que cuantas más endorfinas se liberan en el núcleo accumbens, mayor es el sentimiento de placer, tanto en el bebedor como en el no bebedor. Según los científicos, esto muestra como las endorfinas contribuyen, a largo plazo, al abuso del alcohol y como la liberación de grandes cantidades de endorfinas provoca que la bebida alcohólica sea más placentera, contribuyendo a querer beber más. Sería un indicador de modificación cerebral en los bebedores excesivos o bebedores con problemas, ya que la misma se altera de manera tal que hace que encuentren al alcohol cada vez más placentero.

Los niveles de la proteína MAO-B (29) son más bajos en las plaquetas de los individuos que beben alcohol a niveles peligrosos/dañinos en comparación con los que beben por debajo de este umbral; la medición de la misma podría utilizarse para indicar el nivel de bebida de la persona evaluada. La expresión del gen Drd 2 normal (30) tiene un papel protector contra la inducción del alcohol en la atrofia cerebral; en ausencia de expresión Drd 2, la ingesta de etanol prolongada reproduce en la rata una característica distintiva del alcoholismo humano, la atrofia de las cortezas temporal y parietal. 
Tabla 1. Comparación cantidad de alcohol etílico en el organismo y los cuadros que provoca.

\begin{tabular}{|c|c|c|c|}
\hline $\begin{array}{l}\text { Gramos de alcohol } \\
\text { por litro de sangre }\end{array}$ & Estado mental & Conducta & $\begin{array}{l}\text { Movimientos y } \\
\text { percepciones }\end{array}$ \\
\hline $0-0.5$ & Leve alegría & Apropiada & $\begin{array}{l}\text { Leve lentitud y/o } \\
\text { torpeza }\end{array}$ \\
\hline $0.5-1$ & $\begin{array}{l}\text { Alegría, menor } \\
\text { juicio, menor } \\
\text { concentración }\end{array}$ & Desinhibición social & $\begin{array}{l}\text { Lentitud, torpeza, } \\
\text { disminución del } \\
\text { campo visual }\end{array}$ \\
\hline $1-1.5$ & $\begin{array}{l}\text { Emociones } \\
\text { inestables, } \\
\text { confusión }\end{array}$ & $\begin{array}{l}\text { Descontrol (mal } \\
\text { genio), agresividad }\end{array}$ & $\begin{array}{l}\text { Lengua traposa, } \\
\text { andar tambaleante, } \\
\text { visión doble }\end{array}$ \\
\hline $1.5-2$ & $\begin{array}{l}\text { Incoherencia, } \\
\text { tristeza, rabia }\end{array}$ & $\begin{array}{l}\text { Mayor descontrol, } \\
\text { mareo / vómitos }\end{array}$ & $\begin{array}{l}\text { Dificultad para } \\
\text { hablar y caminar }\end{array}$ \\
\hline $2-3$ & Escasa conciencia & $\begin{array}{l}\text { Apatía e inercia, } \\
\text { incontinencia de } \\
\text { esfínteres }\end{array}$ & $\begin{array}{l}\text { Incapacidad de } \\
\text { hablar y caminar }\end{array}$ \\
\hline $3-4$ & $\begin{array}{l}\text { Coma } \\
\text { (inconciencia) }\end{array}$ & Ausente & $\begin{array}{l}\text { Ausencia de } \\
\text { reflejos y } \\
\text { sensibilidad }\end{array}$ \\
\hline
\end{tabular}

Respecto a la heredabilidad de la dependencia del alcohol, algunos autores consideran que el alcoholismo es un trastorno multifactorial, resultante de la interacción vulnerabilidad genética-alcohol-ambiente y que debe ser entendido en el marco de un modelo ecofarmacogenetico. La vulnerabilidad se podría situar básicamente en dos niveles, el hepático (metabolismo del alcohol) y el nivel neuronal (sensibilidad al efecto del alcohol).

Los estudios en gemelos estiman la predisposición a la dependencia del alcohol de 51 a $65 \%$ en mujeres y de 48 a $73 \%$ en hombres. Respecto a la frecuencia del consumo de alcohol, $66 \%$ en mujeres y de 48 a $73 \%$ en varones. La heredabilidad estimada para el uso temprano del alcohol fue significativamente mayor en muchachos (55\%) que en mujeres jóvenes (11\%).

Aunque existe un componente genético para múltiples aspectos del hábito de beber alcohol, la relación entre genes y conducta del beber no es simple ni está del todo aclarada (31).

El tema del alcoholismo siempre ha sido de interés para la salud, especialmente para la Organización Mundial de la Salud que en su nota descriptiva $N^{\circ} 349$ de Mayo de 2014 informa: 
a. Cada año mueren en el mundo 3,3 millones de personas a consecuencia del consumo nocivo de alcohol, lo que representa un 5,9\% de todas las defunciones.

b. El uso nocivo de alcohol es un factor causal en más de 200 enfermedades y trastornos.

c. En general, el 5,1\% de la carga mundial de morbilidad y lesiones es atribuible al consumo de alcohol, calculado en términos de la esperanza de vida ajustada en función de la discapacidad (EVAD).

d. El consumo de alcohol provoca defunción y discapacidad a una edad relativamente temprana. En el grupo etario de 20 a 39 años, un $25 \%$ de las defunciones son atribuibles al consumo de alcohol.

e. Existe una relación causal entre el consumo nocivo de alcohol y una serie de trastornos mentales y comportamentales, además de las enfermedades no transmisibles y los traumatismos.

f. Recientemente se han determinado relaciones causales entre el consumo nocivo y la incidencia de enfermedades infecciosas tales como la tuberculosis y el VIH/Sida.

g. Más allá de las consecuencias sanitarias, el consumo nocivo de alcohol provoca pérdidas sociales y económicas importantes, tanto para las personas como para la sociedad en su conjunto.(32)

El consumo de alcohol aumenta el riesgo de cáncer oral (cavidad oral, faringe, nasofaringe y el labio), laringe, esófago, mama, colon e hígado. El riesgo de los canceres del tracto aerodigestivo superior (esófago, cavidad oral, faringe, laringe) se incrementa linealmente con la cantidad de alcohol consumido por encima de 25 gr/día. (33).

El consumo prolongado aumenta el riesgo del carcinoma hepatocelular (34); con un aumento del riesgo de tres a seis veces para los mayores consumidores (35).

Incrementa la posibilidad de cáncer de intestino, en un 19\% con $100 \mathrm{mg}$ por semana. Esto se debería a que el acetaldehído, el metabolito primario de alcohol, puede alterar el ADN y causar proliferación celular.

El riesgo de cáncer de mama aumenta un 7 - $12 \%$ por cada 10 gr/día de alcohol (36) mediado por aumento de los niveles de estrógeno que pueden ejercer 
su efecto cancerígeno sobre el tejido mamario. Otros mecanismos pueden incluir el acetaldehído, el estrés oxidativo, los cambios epigeneticos, debido a la transferencia de metilo perturbado y disminución de las concentraciones de ácido retinoico asociados con un ciclo celular alterado (37). Las mujeres no deben exceder de una bebida/día, y las mujeres con riesgo elevado de cáncer de mama deben evitar el alcohol o consumir alcohol solo en ocasiones.

Las borracheras (38) en los adolescentes preocupan, ya que a esa edad, en pleno neurodesarrollo, las bebidas alteran o detienen la evolución normal, siendo las mujeres más vulnerables; hay una disminución de la corteza frontal izquierda en los varones adolescentes, y en mujeres adolescentes con consumo excesivo reciente de alcohol, se halló la corteza cerebral con un grosor disminuido un $8 \%$ en las regiones frontales izquierdas versus las no bebedoras.

Las hepatopatías son responsables del $70 \%$ de la mortalidad por alcohol y tal vez una cuarta parte de la mortalidad atribuible total (39). No importa la cantidad consumida, el hígado solo metaboliza cierta cantidad de alcohol por hora. La velocidad del metabolismo depende parcialmente de la cantidad de enzimas metabolizantes en el hígado que varía entre las personas, y en general después de ingerir una bebida normal, la cantidad de alcohol en sangre alcanza su punto máximo entre los 30 y 45 minutos.

El consumo de alcohol está asociado con un comportamiento sexual de riesgo. Las mujeres en estado de ebriedad, tanto adolescentes como adultas, son más vulnerables al abuso sexual, lo cual contribuye a la carga de morbilidad en términos de adquirir infecciones de transmisión sexual, incluyendo HIV. Hay estudios que demostraron que se usa el alcohol como pretexto para el comportamiento irresponsable, incluyendo sexo de riesgo; también el alcohol permite a los jóvenes "tener valor para abordar una posible pareja sexual" (40).

Además, el consumo nocivo de alcohol puede perjudicar a otras personas, como familiares, amigos, compañeros de trabajo y desconocidos.

Los traumatismos mortales atribuibles al consumo de alcohol tienden a afectar a personas relativamente jóvenes. Incluso se han establecido relaciones causales entre el consumo nocivo y la incidencia de enfermedades infecciosas tales como la tuberculosis y el VIH/Sida. 
El consumo de alcohol por parte de una embarazada puede provocar síndrome alcohólico fetal y complicaciones prenatales.

Hay factores que influyen en el consumo de alcohol y los daños derivados, tanto en el plano individual como el social. Los factores ambientales incluyen el desarrollo económico, la cultura y la disponibilidad de alcohol, así como la globalidad y los niveles de aplicación y cumplimiento de las políticas pertinentes. Para un nivel o hábito de consumo dado las vulnerabilidades de una sociedad podrían tener efectos diferenciales similares a los producidos en diferentes sociedades. Si bien no existe un único factor de riesgo dominante, cuanto más factores vulnerables converjan en una persona, más probable será que esa persona desarrolle problemas relacionados con el alcohol como consecuencia del consumo de alcohol (41).

Esta adicción ocupa el tercer lugar entre los factores de riesgo de carga mundial de morbilidad; es el primer factor de riesgo en las Américas y el Pacifico Occidental y el segundo en Europa. El consumo regular de riesgo alcohólico, en Argentina, fue del $10,7 \%$ a nivel nacional para 2008, con mayor prevalencia en varones entre 50 a 64 años. En tanto, el consumo episódico excesivo de alcohol fue de 8,9\%, con mayor consumo en varones de 18 a 24 años (42).

La edad de inicio disminuyo, siendo el alcoholismo uno de los principales problemas que aquejan a los jóvenes, pero también las mujeres y los ancianos beben más que antes, abarcando de esta manera los segmentos más vulnerables de la población.

En nuestro país se estima que hay casi 2 millones de personas dependientes del alcohol (SEDRONAR), aunque este dato puede ser menor a la realidad ya que se cree que el $92 \%$ de las personas dependientes del alcohol no buscan ayuda profesional para superar su problema.

Existen datos alarmantes que hacen que esta problemática tenga importancia, 30 mil argentinos mueren por año por daños del alcohol en el cerebro, hígado, corazón y otros órganos. El alcohol está presente en más del $50 \%$ de los casos de homicidio, en el $40 \%$ de los casos de accidente de tránsito, y de estos el $78 \%$ son jóvenes entre 17 y 24 años (estos accidentes no son causados por dependientes al alcohol, sino bebedores abusivos ocasionales). El abuso de bebidas alcohólicas es el causante de más del 10\% de los casos que llegan a las 
guardias hospitalarias (sin contar los casos de violencia doméstica, violencia callejera y accidentes de tránsito provocados por alcohol). El tabaco y el alcohol son la puerta de entrada al consumo de drogas ilegales (43).

Desde el punto de vista económico de la salud ocasiona muchas horas perdidas de trabajo, alto nivel de consultas y de gastos médicos orientados hacia el tratamiento de las consecuencias, por lo que se torna prioritario el desarrollo de estrategias de prevención del consumo de alcohol desde edades tempranas, primera y segunda infancia, a fin de evitar el primer contacto en la adolescencia y juventud que definirán el futuro del estado de salud de la población (44).

Si bien los gobiernos de los países en desarrollo reciben con beneplácito la creación de nuevos mercados de alcohol por razones económicas, la puesta en marcha de mecanismos reguladores y de sistemas de tratamiento reciben por lo general menor prioridad (45).

Estos datos reflejan la importancia de conocer esta problemática, para tratarla, pero también para anticiparnos e identificarla a tiempo para prevenirla e impedir su desarrollo.

\subsection{Antecedente familiar de alcoholismo y respuesta frente al estrés}

Existen tres investigaciones que estudiaron si la respuesta hormonal del eje hipotálamo - hipofiso - adrenal frente a una situación de estrés era diferente en individuos con antecedentes familiares de alcoholismo comparado con otros sin estos antecedentes familiares.

El más actual evidenció que la respuesta del cortisol frente a la exposición a una situación de estrés de laboratorio, fue más elevada en un grupo de personas sanas de raza blanca que presentaban antecedentes familiares de alcoholismo en comparación con otro grupo que no presentaban este antecedente en su familia. Hallaron también que la medición de los niveles de ansiedad fue más elevada en sujetos con historia familiar de alcoholismo que en los que no presentaban este antecedente y consideran que una mayor reactividad al estrés está asociada con mayor riesgo de desarrollo de alcoholismo. En el mismo estudio evaluaron otros marcadores como la ACTH y la prolactina. Con ninguna de las dos hormonas se evidenció cambios significativos en sus niveles como efecto de los antecedentes 
familiares de alcoholismo frente a la exposición a una situación de estrés de laboratorio (46).

Otro estudio refiere que los niveles de ACTH fueron menores en aquellos con antecedentes de alcoholismo comparado a quienes no tienen dicho antecedente, y sin diferencias en cuanto al nivel de cortisol (47).

Y la tercera investigación dice que el aumento en los niveles de ACTH y cortisol fue mayor en aquellos con antecedentes de alcoholismo comparado a quienes no tienen dicho antecedente, en varones caucásicos (48).

Los tres estudios realizados hasta el momento presentan resultados contradictorios, algunos mostrando ausencia de diferencia entre los niveles de cortisol, otros confirmando dicha diferencia pero en un subgrupo de gente con diferencias raciales y de género. Algunos estudios confirmando diferencias en los niveles de ACTH, otros negando dicha diferencia.

En este contexto, en el que la evidencia actual es poco clara al respecto, se decidió realizar el presente estudio, con el fin de aportar mayor evidencia científica sobre el tema.

La intención de este estudio fue determinar si existen diferencias en la respuesta del eje Hipotálamo-hipofiso-adrenal frente a una situación de estrés psicosocial, entre individuos con antecedente familiar de alcoholismo y otros sin este antecedente.

Esta determinación permitiría trabajar en el área traslacional de la medicina identificando a una población sana en riesgo potencial y así anticiparse al desarrollo de trastornos relacionados con el estrés y el alcoholismo. Esto favorecería a la calidad de vida de esta población y a disminuir los gastos en salud.

Palabras clave: estrés, cortisol, abuso y dependencia al alcohol, antecedentes familiares, estudiantes universitarios. 


\subsection{Problema de estudio}

Determinar si existen diferencias significativas en la respuesta hormonal ante el estrés agudo entre estudiantes de medicina de la Universidad Adventista del Plata con y sin antecedentes familiares de abuso y/o dependencia al alcohol, entre julio y noviembre de 2009.

\subsection{Objetivo}

“Determinar si existen diferencias significativas en la respuesta del eje Hipotalamo-hipofiso-adrenal mediante la medición de cortisol plasmático frente a una situación estresante entre estudiantes con y sin antecedentes familiares de abuso y/o dependencia al alcohol."

\subsection{Hipótesis}

Los individuos que presenten antecedentes familiares de trastorno por consumo de alcohol tendrían niveles más altos en la secreción de cortisol frente a una situación estresante, que aquellos que no lo presenten. 


\section{MATERIALES Y MÉTODOS}

\section{1 Ámbito y duración de estudio}

El presente estudio se realizó en la Universidad Adventista del Plata. La duración del mismo fue de 4 meses, se efectuó entre Agosto y Noviembre del año 2009.

Esta Institución se encuentra ubicada en la Localidad de Libertador San Martin, departamento Diamante, a $60 \mathrm{~km}$ de la ciudad de Paraná, capital de la provincia de Entre Ríos. La Universidad Adventista del Plata (UAP) forma parte del sistema educativo que la Iglesia Adventista del Séptimo Día sostiene alrededor del mundo. Cuenta con un alumnado de 3000 individuos provenientes de 52 nacionalidades. Tiene una Facultad de Ciencias de la Salud, donde se encuentra la Carrera de Medicina con unos 600 alumnos y 252 docentes aproximadamente.
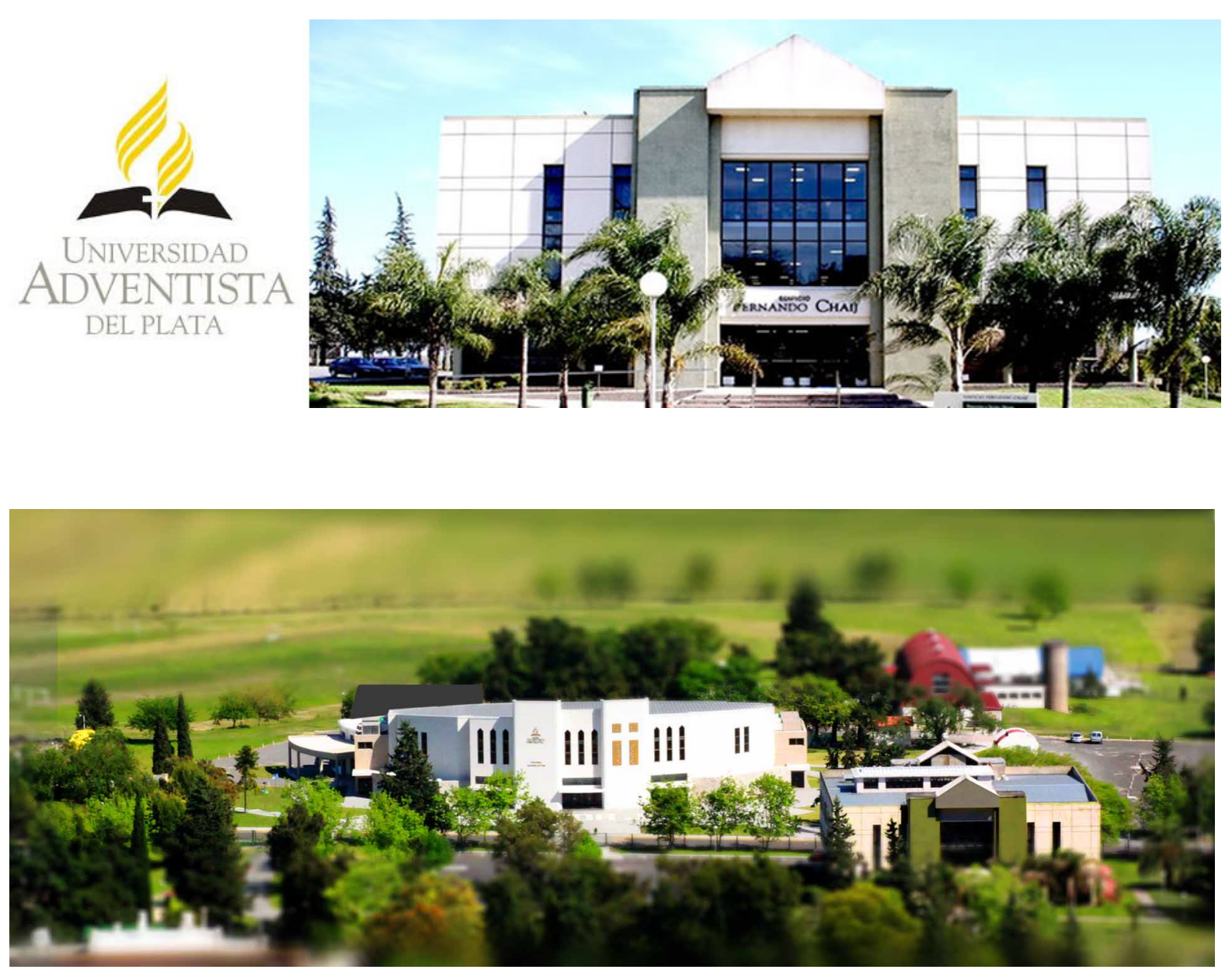


\subsection{Diseño del estudio}

El diseño que se aplicó fue experimental, prospectivo, longitudinal.

\subsection{Métodos de muestreo}

El universo estuvo constituido por estudiantes caucásicos de la carrera de medicina de la Universidad Adventista del Plata (UAP) no alcohólicos con antecedentes familiares de alcoholismo en la primera o segunda generación (AFP) y estudiantes de la UAP caucásicos no alcohólicos sin antecedentes familiares de alcoholismo en la primera o segunda generación (AFN).

Por motivos de factibilidad se trabajó con una población de estudiantes de la carrera de medicina, integrada por individuos que cumplen los criterios de inclusión.

\subsubsection{Criterios de inclusión}

1. Estudiantes universitarios de la carrera de medicina de la UAP que no cumplan con los criterios del DSM IV para abuso o dependencia alcohólica.

2. Edad de 18 a 35 años con antecedentes de historia familiar de abuso o dependencia alcohólica.

3. Edad de 18 a 35 años sin antecedentes de historia familiar de abuso o dependencia alcohólica.

\subsubsection{Criterios de exclusión}

1. Negativa a participar del estudio.

2. Presencia de patología psiquiátrica activa.

3. Presencia de enfermedad neurológica activa.

4. Tabaquismo activo.

\section{4 Instrumentos}

La selección de los individuos se realizó con la aplicación de la Mini International Neuropsychiatric Interview (M.I.N.I.) (49, 50, 51) y el Family Tree Questionnaire (FTQ). (52, 53).

La M.I.N.I. es una entrevista diagnóstica estructurada de breve duración que explora los principales trastornos psiquiátricos del eje I del DSM IV y el ICD 10. Estudios de validación y de confiabilidad se han realizado comparando la M.I.N.I. 
con la SCIPD para el DSM III-R y el CIDI (una entrevista estructurada desarrollada por la Organización Mundial de la Salud para entrevistadores no clínicos para el ICD 10). Los resultados de estos estudios demuestran que la M.I.N.I. tiene un puntaje de validación y confiabilidad aceptable alto, que además puede ser administrado en un periodo de tiempo mucho más breve (promedio de 18.7 +- 11.6 minutos, media 15 minutos) que las otras escalas mencionadas. Puede ser utilizada por clínicos luego de una breve sesión de entrenamiento.

EI FTQ es fácilmente aplicable, breve y puede evaluar la historia familiar con problemas de alcoholismo. Consta de un diagrama del árbol familiar con claves para identificar familiares con problemas con alcohol. Es confiable para evaluar parientes de primer grado (padres y hermanos) y de segundo grado (abuelos tías y tíos). El tiempo de administración es aproximadamente 5 minutos. Puede ser administrado por el investigador o personas entrenadas o también puede ser auto administrado.

Se utilizó como instrumento de recolección de datos la M.I.N.I, FTQ, el Trier Social Stress Test (TSST) (54), una entrevista semiestructurada y la toma de muestras biológicas. (Ver anexos).

Para la determinación de cortisol en plasma, fueron evaluados entre las 7.30 hs y 10 hs de la mañana, con el individuo en ayunas y los siguientes recaudos: espera inicial de 10 minutos en un salón del laboratorio de estrés, apartado y tranquilo antes de la extracción inicial. Se realizó luego el procedimiento de extracción en el mismo salón en condiciones de asepsia, lo realizaron técnicos enfermeros entrenados en esta práctica, se usaron jeringas hipodérmicas estéril de $10 \mathrm{ml}$ descartable con aguja hipodérmica $21 \mathrm{G} \times 25 \mathrm{~mm}$.

Se usaron reactivos "CORTISOL" marca ROCHE COBA, test inmunológico in vitro para determinación cuantitativa de cortisol en suero, año 2009.

Se utilizó el método electroquimioluminiscencia, empleado para analizadores automático Roche ELECSYS 2010 ECLIA ROCHE, en Laboratorio del Sanatorio Adventista del Plata, con controles internos de calidad y externos por el "Programa Buenos Aires XXIII de control de calidad - CEMIC".

Las extracciones basales se realizaron en la franja horaria de las 7.30 a 10 AM por lo que se toma el valor normal basal de 6.2 a $19.4 \mathrm{mcg} / \mathrm{dl}$.

Las mediciones fueron evaluados de forma basal (Pretest) y luego de aplicada la intervención fueron medidas nuevamente (Postest), entre 30 y 35 
minutos posteriores a la primera muestra, ambas determinaciones fueron efectuadas a todos los participantes.

\section{5 Operacionalización de variables}

A. Variable dependiente: nivel de cortisol en sangre (variable cuantitativa continua expresado en $\mathrm{mcg} / \mathrm{dl})$.

B. Variables independientes:

a. Tiempo: (variable cualitativa nominal con 2 niveles).

(a) Pretest

(b) Postest

b. Grupos: (variable cualitativa nominal con 2 niveles).

(a) Participantes con antecedente familiar de alcoholismo

(b) Participantes sin antecedente familiar de alcoholismo

c. Sexo: (variable cualitativa nominal con 2 niveles).

(a) Femenino

(b) Masculino

d. Edad: (variable cuantitativa continua, en años cumplidos).

e. Nacionalidad: (variable cualitativa nominal).

f. Religión: (variable cualitativa nominal).

g. Estado civil: (variable cualitativa nominal).

h. Trabajador: (variable cualitativa nominal). 


\section{6 La intervención}

La intervención consistió en la aplicación del Test de Estrés Social de la Universidad de Trier (TRIER SOCIAL STRESS TEST- TSST).

EI TSST es un procedimiento desarrollado en la Universidad de TRIER (Alemania) para la inducción de un estado de estrés moderado, bajo condiciones de laboratorio evaluando especialmente los cambios producidos en la actividad del eje hipotálamo-hipófisis-suprarrenal (HHA). En los numerosos estudios en TRIER y otros laboratorios, el TSST ha demostrado generar cambios significativos en los parámetros cardiovasculares, en diferentes vías endocrinas así como en valoraciones de tensión subjetivas.

EI TSST consiste en el desarrollo de varios pasos, en primer lugar el individuo llega al laboratorio donde es recibido por un encargado, y reposa 10 minutos en un salón tranquilo (S1), luego se le extraen 8-10 $\mathrm{ml}$ de sangre (muestra pretest), posteriormente se lo lleva a otro salón (S 2) donde se encuentra un tribunal compuesto por 4 personas, una cámara filmadora, un micrófono multidireccional y una luz directa a un sector donde se ubicara la persona. El tribunal está compuesto por profesionales médicos psiquiatras de vasta experiencia. Allí el encargado le explica al participante que tendrá que preparar un discurso con el cual deberá convencer a este tribunal que él es la persona más adecuada para ingresar a la carrera de medicina de esta universidad, esto será filmado grabado y medido por un sistema para detectar señales de tensión nerviosa, y que los miembros del tribunal son expertos en detectar estas señales. Luego de la explicación si no hay preguntas se lo lleva nuevamente al S1 y se le dan 10 minutos para preparar su discurso, se le provee lápiz y papel para anotaciones pero se le aclara que no podrá llevarlos a la exposición. Al cumplirse el tiempo se lo traslada nuevamente al S2 donde el presidente del tribunal le solicita el nombre y le dice que comience con su discurso, se lo deja hablar durante 5 minutos, mientras el tribunal lo observa pueden hacer anotaciones, si el participante termina su discurso antes de los 5 minutos el presidente del tribunal puede hacer preguntas hasta que se cumpla el tiempo. Seguidamente se le solicita que realice un cálculo matemático que presenta dificultad como por ejemplo descender en pasos de 13 números hasta llegar a 0 , lo más rápidamente posible desde el número 2011, cada vez que la persona se equivoque el presidente del tribunal dice "error" y el participante debe comenzar de 
nuevo, esto durante 5 minutos, luego de lo cual se le dice "suficiente" y se lo retira del salón. Al salir es recibido por el encargado quien se ocupa de explicar al participante que lo que acaba de hacer es una simulación, que no se ha filmado ni grabado su discurso y que esto era para provocar un estado de tensión para el estudio, se espera unos 10 minutos y se le extrae nuevamente sangre (muestra post test).

\section{7 Procedimiento de colecta de datos}

En el desarrollo del estudio cada sujeto empleó aproximadamente 60 minutos en el laboratorio. De ese tiempo, unos 20 minutos fueron usados en el protocolo de tensión psicológico real, el tiempo restante fue empleado en la introducción al TSST, toma de muestras biológicas y preguntas.

La aplicación del método del TSST se llevó a cabo, en el proceso de investigación, en dos etapas:

1. Prueba Piloto: esta prueba tuvo como objetivo ajustar la técnica de aplicación del TSST en un grupo de individuos que no formaron parte del muestreo definitivo. Para ello se reclutaron cinco individuos graduados de la carrera de medicina, que habían terminado sus estudios el año anterior, y se les aplico el TSST.

2. Desarrollo y aplicación del objetivo propuesto en el presente trabajo.

\section{8 Análisis estadístico}

La edición, carga y análisis de los datos se realizó con la utilización del paquete estadístico SPSS 11.0 para Windows. Las diferencias en características demográficas basales fueron analizadas con la prueba $\mathrm{T}$ de Student para las variables continuas y con la prueba chi cuadrado para las variables categóricas. La T de Student es una distribución de probabilidad, que surge del problema de estimar la media de una población normalmente distribuida cuando el tamaño de la muestra es pequeño. Para ello se utiliza la "prueba de la t de student", para la determinación de las diferencias entre dos medias muestrales y para la construcción del intervalo de confianza para la diferencia entre las medias de dos poblaciones. Las pruebas chi cuadrado son un grupo de contraste de hipótesis que sirven para comprobar afirmaciones acerca de las funciones de probabilidad de una o dos variables 
aleatorias. Una medida de discrepancia existente entre las frecuencias observadas y esperadas es suministrada por el chi cuadrado. Cuando es 0 las frecuencias observadas y esperadas concuerdan exactamente, mientras que si es mayor a 0 , no coinciden exactamente. A valores mayores de chi cuadrado, mayores son las discrepancias entre las frecuencias observadas y esperadas. Si las frecuencias esperadas son al menos iguales a 5, la aproximación mejora para valores superiores. En la práctica las frecuencias esperadas se calculan de acuerdo con la hipótesis 0 . Si bajo esta hipótesis el valor calculado de chi cuadrado dado es mayor que algún valor crítico, se deduce que las frecuencias observadas difieren significativamente de las esperadas y se rechaza la hipótesis 0 al nivel de significación correspondiente. En caso contrario no se rechazara. Este procedimiento se llama ensayo o prueba de chi cuadrado de la hipótesis.

Se usó la prueba ANOVA para medidas repetidas a fin de determinar la diferencia en los niveles de cortisol entre ambos grupos en las mediciones pre y post test. EI ANOVA o análisis de varianza es un método para comparar dos o más medias en varias situaciones.

Se usaron tests Post hoc para describir la dirección de la diferencia y se empleó un nivel de significancia de $p<0.05$. Las pruebas post hoc son múltiples técnicas que se utilizan para identificar en que grupos se produjeron las diferencias. También se calculó el poder estadístico con el fin de evaluar la capacidad de hallar las conclusiones esperadas del presente estudio. El poder estadístico representa la probabilidad de rechazar la hipótesis nula cuando realmente es falsa, es decir que representa la capacidad de un test para detectar como estadísticamente significativas las diferencias o asociaciones de una magnitud determinada. 


\section{RESULTADOS}

En la Tabla 1 se detallan las características de los participantes del estudio, en ella se puede observar que entre varones y mujeres hubo 76 individuos, 31 masculinos y 45 femeninos (ver figura 2 ).

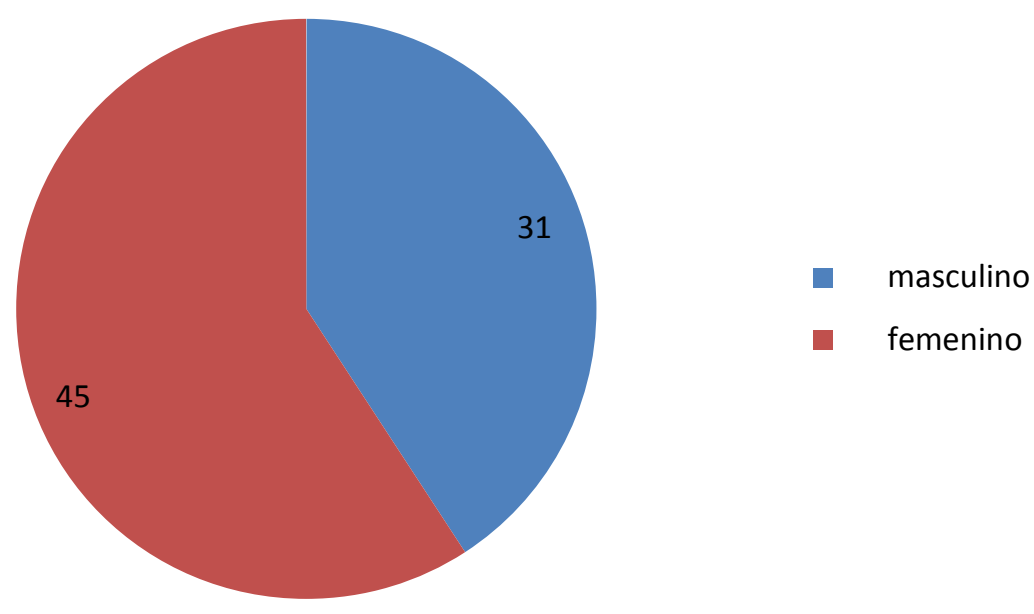

Figura 2. Distribución de sujetos según sexo.

La edad media fue de 22.4 años.

En el grupo con antecedentes familiares de alcoholismo en la primera o segunda generación $\circ$ antecedentes familiares positivos (AFP) hubo 35 participantes (9 masculinos y 26 femeninos). El grupo sin antecedentes familiares de alcoholismo en la primera o segunda generación o antecedentes familiares negativos (AFN) tuvo 41 participantes (22 masculinos y 19 femeninos).

El estado civil fue predominantemente solteros con 71 individuos (31 AFP y $40 \mathrm{AFN}$ ), casados 3 individuos (2 AFP y $1 \mathrm{AFN}$ ), divorciado 1 individuo que integra el grupo con antecedentes familiares de alcoholismo (AFP) y 1 individuo que no contesto sobre su estado civil. 
La totalidad de la muestra son estudiantes universitarios, de los cuales 50 no trabajan (24 AFP y 26 AFN), 5 trabajan (2 AFP y 3 AFN) y 21 no contestaron sobre actividad laboral (9 AFP y 12 AFN).

La religión de los participantes fue 59 personas Adventistas (29 AFP y 30 AFN), Bautista 1 que no presentaba antecedentes familiares de alcoholismo, Católicos 10 (2 AFP y 8 AFN), Cristiana Evangélica 1 con antecedentes familiares de alcoholismo, Mormón 1 sin antecedentes familiares de alcoholismo, y no contestaron esta pregunta 4 participantes (3 AFP y 1 AFN).

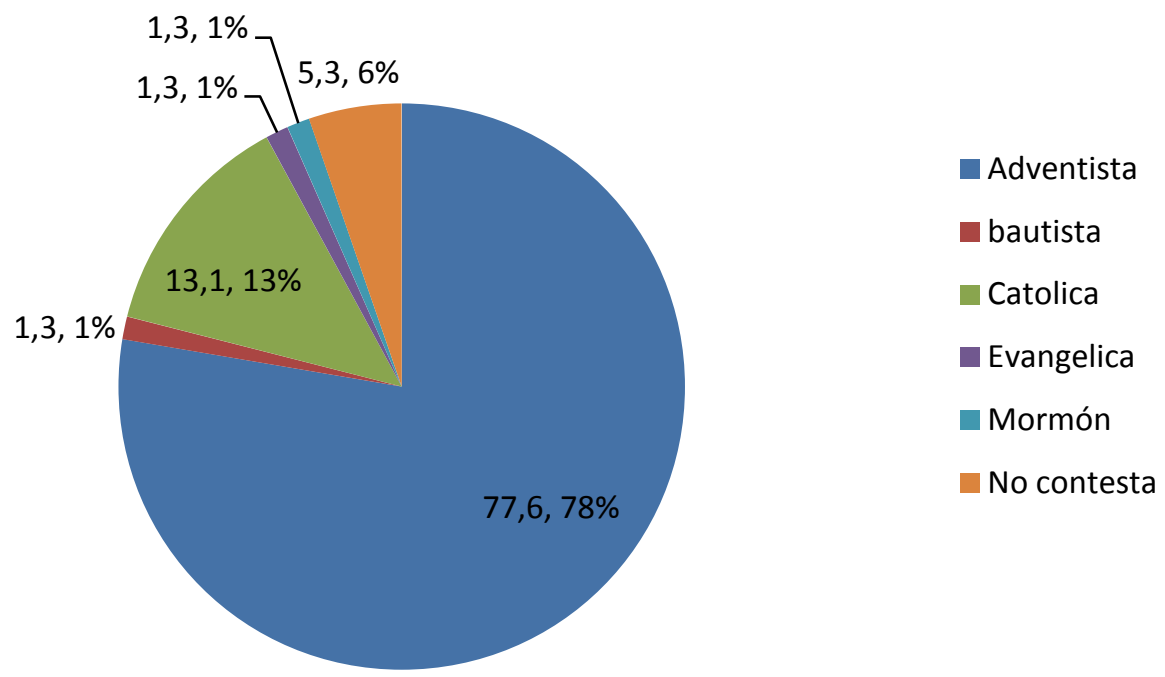

Figura 3. Distribución de sujetos según religión.

Respecto a la nacionalidad de los participantes hubo 37 Argentinos (12 AFP y 25 AFN), 12 Chilenos (8 AFP y 4 AFN), 11 Brasileros (7 AFP y 4 AFN), 4 Colombianos (2 AFP y 2 AFN), 4 Peruanos (2 AFP y 2 AFN), 2 Paraguayos (1 AFP y 1 AFN), 1 Panameño sin antecedentes familiares de alcoholismo, 1 Mexicano sin antecedentes familiares de alcoholismo, 1 Ecuatoriano con antecedentes familiares de alcoholismo, 1 Noruego con antecedentes familiares de alcoholismo, 1 Ucraniano con antecedentes familiares de alcoholismo, 1 Filipino sin antecedentes familiares de alcoholismo (ver figura 4). 


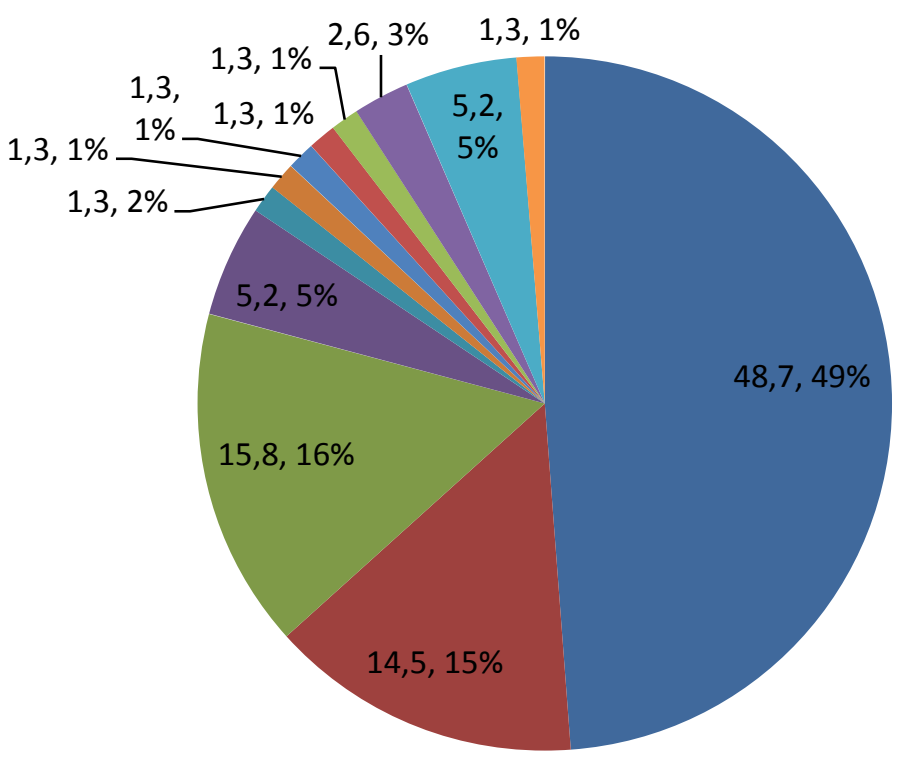

$$
\begin{aligned}
& \text { - Argentina } \\
& \text { - Brasileña } \\
& \text { - Chilena } \\
& \text { - Colombiana } \\
& \text { - Ecuatoriana } \\
& \text { - Filipina } \\
& \text { - Mexicana } \\
& \text { - Noruega } \\
& \text { - Panameña } \\
& \text { - Paraguaya } \\
& \text { - Peruana } \\
& \text { - Ucraniana }
\end{aligned}
$$

Figura 4. Distribución de sujetos según nacionalidad.

En relación al cortisol basal, este tuvo una media de $16.2 \mathrm{mcg} / \mathrm{dl}$ en la totalidad de la muestra, siendo de $14.7 \mathrm{mcg} / \mathrm{dl}$ en el grupo con antecedentes familiares de alcoholismo (AFP) y de $17.5 \mathrm{mcg} / \mathrm{dl}$ en quienes no presentan antecedentes familiares de alcoholismo (AFN). Todos los sujetos que participaron del estudio eran estudiantes de la carrera de medicina de la Universidad Adventista del Plata. 
Tabla 2. Características basales de los participantes del estudio

\begin{tabular}{|c|c|c|c|c|}
\hline Variable & Participantes & $\begin{array}{c}\text { Con } \\
\text { antecedente } \\
\text { familiar de } \\
\text { alcoholismo } \\
(n=35)\end{array}$ & $\begin{array}{c}\text { Sin } \\
\text { antecedente } \\
\text { familiar de } \\
\text { alcoholismo } \\
(n=41)\end{array}$ & $p$ \\
\hline Edad \# & $22.4(4.4)$ & $\begin{array}{r}23.3(6.5) \\
9(25.7) \\
26(74.2)\end{array}$ & $\begin{array}{l}21.7(2.3) \\
22(53.6) \\
19(43.3)\end{array}$ & $\begin{array}{c}0.187 \\
0.013^{*}\end{array}$ \\
\hline $\begin{array}{l}\text { Nacionalidad } \\
\text { Argentina } \\
\text { Chilena } \\
\text { Brasilera } \\
\text { Colombiana } \\
\text { Peruana } \\
\text { Paraguaya } \\
\text { Panameña } \\
\text { Mexicana } \\
\text { Ecuatoriana } \\
\text { Noruega } \\
\text { Ucraniana } \\
\text { Filipina }\end{array}$ & $\begin{array}{l}37(48.6) \\
12(15.7) \\
11(14.4) \\
4(5.2) \\
4(5.2) \\
2(2.7) \\
1(1.3) \\
1(1.3) \\
1(1.3) \\
1(1.3) \\
1(1.3) \\
1(1.3)\end{array}$ & $\begin{array}{l}12(32.4) \\
8(66.6) \\
7(63.6) \\
2(50) \\
2(50) \\
1(50) \\
0 \\
0 \\
1(100) \\
1(100) \\
1(100) \\
0\end{array}$ & $\begin{array}{l}25(67.5) \\
4(33.3) \\
4(36.3) \\
2(50) \\
2(50) \\
1(50) \\
1(100) \\
1(100) \\
0 \\
0 \\
0 \\
1(100)\end{array}$ & 0.340 \\
\hline $\begin{array}{l}\text { Religión } \\
\text { Adventista } \\
\text { Bautista } \\
\text { Católica } \\
\text { Cristiana Evangélica } \\
\text { Mormon } \\
\text { No contesta }\end{array}$ & $\begin{array}{c}59(77.6) \\
1(1.3) \\
10(13 .) \\
1(1.3) \\
1(1.3) \\
4(5.2)\end{array}$ & $\begin{array}{l}29(49.1) \\
0 \\
2(20) \\
1(100) \\
0 \\
3(75)\end{array}$ & $\begin{array}{l}30(50.8) \\
1(100) \\
8(80) \\
0 \\
1(100) \\
1(25)\end{array}$ & 0.270 \\
\hline $\begin{array}{l}\text { Estado civil } \\
\text { Soltero } \\
\text { Casado } \\
\text { Divorciado } \\
\text { No contesta }\end{array}$ & $\begin{array}{r}71(93) \\
3(3.9) \\
1(1.3) \\
1(1.3)\end{array}$ & $\begin{array}{c}31(43.6) \\
2(66.6) \\
1(100) \\
1(100)\end{array}$ & $\begin{array}{l}40(56.3) \\
1(33.3) \\
0 \\
0\end{array}$ & 0.187 \\
\hline $\begin{array}{l}\text { Trabaja } \\
\text { Si } \\
\text { No } \\
\text { NC } \\
\text { Cortisol basal \# }\end{array}$ & $\begin{array}{c}5(6.5) \\
50(65.7) \\
21(27.3) \\
16.2(5.5)\end{array}$ & $\begin{aligned} & 2(40) \\
& 24(48) \\
& 9(42.8) \\
& 14.7(5.7)\end{aligned}$ & $\begin{aligned} & 3(60) \\
& 26(52) \\
& 12(57.1) \\
& 17.5(5.3)\end{aligned}$ & $0.036^{*}$ \\
\hline
\end{tabular}

\# Datos expresados en media y desvío estándar

* Estadísticamente significativas: $p<0.05$ 
En relación a los resultados relacionados con las hipótesis de la investigación presente, se realizó un análisis de variancia, cuyos datos se observan a continuación. En la figura 5 se muestra que los individuos SIN antecedentes familiares de alcoholismo tuvieron una tendencia a tener niveles mayores de cortisol que los del grupo CON antecedentes familiares de alcoholismo, tanto en el pretest como en el postest (ver tabla 2).

Mediante el ANOVA realizado se observa que no existen diferencias significativas en los niveles de cortisol en respuesta al estrés agudo entre participantes con y sin antecedentes de alcoholismo familiar ( $F=2,64 \quad(1,71)$; $p=0,108)$. Se halló un valor de potencia estadística de 0.361 , por lo cual se infiere que la capacidad del estudio de encontrar las diferencias esperadas, en el caso de que existiesen seria de $36 \%$.

Por otro lado, sí existen diferencias significativas en los niveles de cortisol en respuesta al estrés en función de la variancia intrasujeto medida a través del test $y$ retest $(f=68,038(1,71) ; p=0,000)$. 


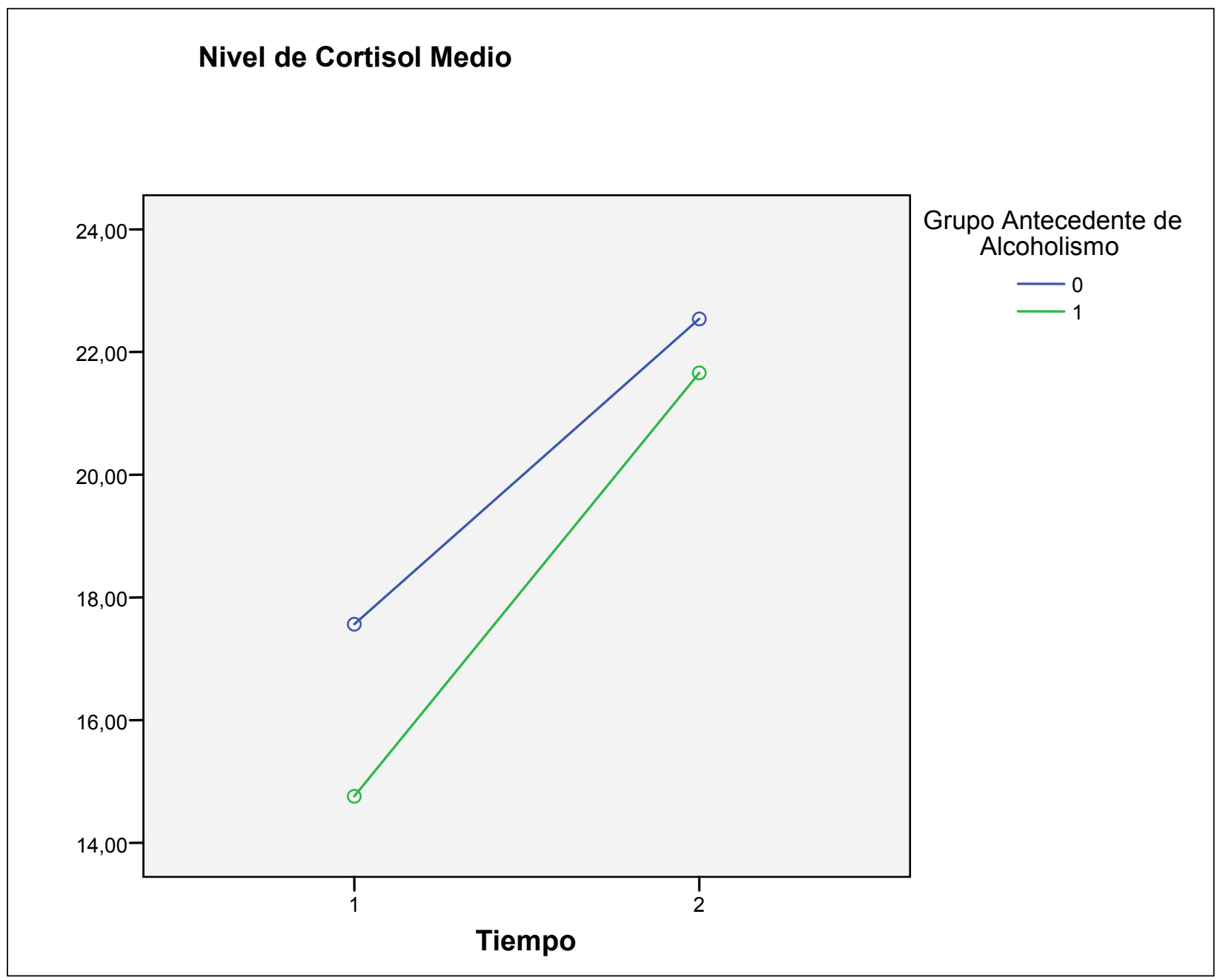

Tiempo (Mediciones 1 y 2)

Figura 5. Medias en función de grupos CON y SIN antecedentes de alcoholismo y de la variable tiempo. (Verde: grupo CON antecedentes de alcoholismo; azul: grupo SIN antecedentes de alcoholismo)

Tabla 3. Medias y desvíos según antecedentes de alcoholismo y la variable tiempo.

Antecedentes de

\begin{tabular}{lcc} 
Alcoholismo & Cortisol basal & Cortisol post test \\
\hline Con antecedentes & $14.76(\mathrm{DE}=5.82)$ & $21.66(\mathrm{DE}=5.49)$ \\
Sin antecedentes & $17.56(\mathrm{DE}=5.41)$ & $22.54(\mathrm{DE}=6.12)$ \\
\hline
\end{tabular}




\section{DISCUSIÓN}

El presente trabajo no encontró diferencias estadísticamente significativas, entre los grupos con y sin antecedentes de alcoholismo familiar respecto a la respuesta del eje Hipotálamo- Hipofiso - Adrenal (HHA), representada por la respuesta del cortisol al estrés agudo.

La respuesta del cortisol presentó una elevación significativa en respuesta a la situación de estrés para ambos grupos, probando la efectividad del método usado para provocar estrés, pero no logrando demostrar diferencias significativas en dicha respuesta.

Tres estudios examinaron la relación de la respuesta hormonal del eje HHA a un estrés psicosocial con historia familiar de alcoholismo. (Uhart, et al. 2006, Zimmermann, et al. 2004, Dai, et al. 2002).

Uhart, et al, realizaron un estudio para determinar si las hormonas del estrés y la respuesta subjetiva frente a la exposición de estrés psicosocial era diferente en personas no alcohólicas descendientes de familias con historia de dependencia de alcohol (FHP), así como en individuos no alcohólicos descendientes de familias sin antecedentes de dependencia de alcohol (FHN). Evaluaron 45 individuos, 17 FHP y $28 \mathrm{FHN}$, entre los 18 y 29 años quienes realizaron un test de exposición a estrés psicosocial (TSST). Se tomaron muestras sanguíneas antes y luego de la realización de la prueba con medición de Cortisol, ACTH y prolactina. Y se realizaron mediciones de ansiedad con un test de auto administración.

Zimmermmann et al, realizaron un estudio donde se testearon dos hipótesis:

1. Que una historia familiar de alcoholismo estaría asociada con una respuesta aumentada al estrés y

2. Que la respuesta al estrés sería más efectiva con consumo de alcohol.

Estudiaron 29 sujetos con alto riesgo con historia paterna de alcoholismo y 23 individuos controles con una historia familiar negativa para alcoholismo. La edad fue entre 18 y 26 años, reclutados en una muestra representativa de un área de la población local. Se expusieron a una prueba de estrés psicosocial (TSST) luego de 
haber bebido placebo o una bebida con alcohol $(0.6 \mathrm{gr} / \mathrm{kg})$, en un diseño randomizado doble ciego cruzado.

Las observaciones de Uhart y Zimmerman demostraron que en pacientes caucásicos masculinos con historia familiar de alcoholismo, la respuesta del cortisol y ACTH al estrés agudo (TSST) fue mayor comparado con quienes no tenían historia de alcoholismo.

Por otra parte Dai reportó hallazgos diferentes en un trabajo en el cual indujo bajos niveles de estrés, por ejemplo, un aumento en la secreción de ACTH en personas con historia familiar de alcoholismo comparado con otras sin ella, frente a la ausencia de diferencias en la respuesta del cortisol a la historia familiar de alcoholismo.

Dai et al, investigaron la respuesta del eje Hipotálamo-Hipofiso-Adrenal frente al estrés y los efectos del etanol en la respuesta de estrés en individuos con alto riesgo de alcoholismo (HR) y otros con bajo riesgo (LR) de alcoholismo según su historia familiar. Evaluaron veinte sujetos HR y veinte sujetos LR que realizaron un trabajo de inducción al estrés de 30 minutos siguiendo la ingesta de una bebida placebo o una baja dosis de etanol. Los niveles en plasma de ACTH y cortisol fueron medidos antes de, y por cuatro horas posteriores al inicio del tratamiento.

Los cambios en el tiempo en los niveles de hormonas en plasma que seguían a la ingesta de bebida placebo o etanol, sin la realización del trabajo de estrés sirvieron como controles para comparar los cambios inducidos por el estrés.

Nuestros hallazgos son coincidentes con los de Dai et al en lo que respecta al cortisol, que fue el objeto de nuestro estudio, donde no se evidencio respuesta en función de la historia familiar de alcoholismo. Aunque, si encontramos una diferencia estadísticamente significativa en los niveles basales de cortisol entre los grupos con y sin antecedentes familiares de alcoholismo (media de cortisol basal en el grupo con antecedentes de alcoholismo de 14,76 mcg/dl; $p=0.036)$; media de cortisol basal en el grupo sin antecedentes de alcoholismo $17,56 \mathrm{mcg} / \mathrm{dl}$ y se evidencio un incremento significativo de la respuesta del cortisol frente a la exposición al estrés (TSST) en toda la muestra estudiada, pero no hubo diferencias posteriores a la exposición a estrés entre ambos grupos. (Media de cortisol post test en el grupo sin antecedentes de alcoholismo $22,54 \mathrm{mcg} / \mathrm{dl}$; media de cortisol post test grupo con antecedentes de alcoholismo 21,66 mcg/dl) 
Es posible, que diferencias en la población reclutada, en la clasificación de historia familiar, características del estresor y composición racial y métodos puedan explicar la discrepancia entre ambos estudios.

La población evaluada por nosotros es reclutada de un ámbito universitario de Libertador San Martin, todos son estudiantes de la carrera de Medicina, la de Dai son reclutadas de colegios y universidades de Montreal, lo cual puede hacer que sean de características muy similares. En cambio la muestra de Zimmerman es tomada de la población general de Munich, y la de Uhart de la población general de Baltimore, lo cual daría cierta coincidencia poblacional entre ellos. Se sabe que un estímulo genera menor impacto de estrés al pasar de ser inédito o desconocido a ser conocido o familiar y menor aun en las repeticiones posteriores, por lo tanto se puede estimar que un estudiante (como los que integran la población de Dai y del presente estudio) estaría más familiarizado con evaluaciones cognitivas como las que se presentan en el TSST, comparado con individuos de la población general (como los que integran el estudio de Zimmermann y de Uhart).

Otro dato a tener en cuenta es el criterio que se usó para determinar la historia familiar de alcoholismo. En el caso de Dai se tomó como de alto riesgo los individuos que tenían padre y abuelo alcohólico (2 generaciones), los que tenían madres con antecedentes alcohólicos se los excluyo por el riesgo a la exposición en la vida fetal. En el caso de Zimmermann, para determinarlo con historia familiar positiva debía tener el padre con antecedentes de alcoholismo, no así la madre. Para Uhart los que presentaban historia familiar positiva tenían a ambos padres, o uno de ellos, o uno o más de la segunda generación (abuelos). En nuestro caso también debían tener antecedentes de alcoholismo en la primera y/o segunda generación, es decir padres o abuelos. En futuros estudios podría ser interesante ser más estricto en este criterio y evaluar la respuesta del cortisol en personas que tengan antecedentes directos en la primera generación y compararlos con otros que no tengan antecedentes.

La composición racial fue de caucásicos y afroamericanos para Uhart y solo de caucásicos para los demás, incluido nuestro estudio. Las discusiones aquí descriptas se basan en los resultados sobre caucásicos.

En relación al género, Dai y Zimmerman solo evalúan masculinos debido a la dificultad del control de fase de ciclo menstrual y uso de anovulatorios. Uhart 
incluyó tanto masculinos como femeninos, pero estas últimas no utilizaban métodos hormonales anticonceptivos, y se encontraban en la fase folicular del ciclo menstrual. En nuestro caso se incluyó a ambos sexos y solo se chequeo mediante un interrogatorio que los femeninos no utilizaran métodos hormonales anticonceptivos, ni de otro tipo, lo cual puede ser una fuerte limitación en la interpretación de los resultados. Se sabe que hay una variación con una mayor respuesta en la fase lútea (progestacional), sugiriendo que las mujeres en esta fase pueden tener mayor sensibilidad suprarrenal.

En lo que respecta al método, Dai tomo 12 muestras de $5 \mathrm{ml}$ de sangre para la estimación de ACTH y cortisol. El horario de extracción de las muestras fue entre las 8 y 9 de la mañana. En nuestro caso las extracciones se hicieron entre las 7:30 y 10 hs de la mañana y solo se extrajeron 2 muestras, una pre test y otra post test. Es decir que se midieron los niveles de cortisol en el momento donde la curva hace su pico máximo de concentración en plasma en ambos estudios. Zimmermann en cambio tomo las muestras a partir de las 14 hs y fueron 9 entre pre y post exposición al estrés. Uhart tomo 3 muestras pre exposición de estrés y 5 muestras post test cada 15 minutos y fueron a partir de las 12 hs del mediodía. En estos horarios la curva del cortisol disminuye respecto al pico matinal.

La congruencia de resultados se da entre Zimmerman y Uhart por un lado y entre Dai y nuestro estudio por el otro siendo coincidentes los horarios de tomas de las muestras también entre cada par de estudios.

El cortisol posee un ritmo de secreción con un pico matinal consecuencia de una serie progresiva de pulsos de ACTH de mayor frecuencia y amplitud que comienza en la última parte del sueño y se prolonga en las primeras horas de la vigilia, una disminución hacia el mediodía y disminuye notoriamente hacia la tarde, presentándose el nadir de la secreción de cortisol a la noche (55). Se desconoce si la sensibilidad del cortisol sería diferente en los distintos momentos de la curva circadiana, pero llama la atención que en los estudios evaluados al mediodía, en los momentos que normalmente el cortisol va descendiendo se encuentran diferencias significativas entre los individuos con antecedentes de alcoholismo y en los que no presentan este antecedente. No así en los estudios realizados en el momento de pico de concentración del cortisol (matinal), como es el caso de nuestro estudio. Esto podría ser objeto de estudios futuros. 
En suma se concluye que no existen diferencias significativas en los niveles de cortisol en respuesta al estrés agudo entre participantes con y sin antecedentes de alcoholismo familiar.

Recordemos que el objetivo que nos planteamos investigar en este trabajo era determinar si existen diferencias significativas en la respuesta del eje Hipotálamo-hipofiso-adrenal mediante la medición de cortisol plasmático frente a una situación estresante entre estudiantes, con y sin antecedentes familiares de abuso y/o dependencia al alcohol. Y frente a este problema se planteó la hipótesis de que los individuos que presenten antecedentes familiares de trastorno por consumo de alcohol tendrían niveles más altos en la secreción de cortisol frente a una situación estresante, que aquellos que no lo presenten, estimando de esa forma mayor sensibilidad al estrés y teniendo en cuenta la vulnerabilidad que se conoce en los familiares de alcohólicos a desarrollar esta enfermedad. Pero luego de la realización del mismo encontramos que la hipótesis no pudo ser confirmada debido a que no se encontró diferencias significativas en los niveles de cortisol en respuesta al estrés agudo en el grupo de participantes con antecedentes de alcoholismo familiar comparado con aquellos que no presentaban este antecedente. Aunque es interesante destacar que se hallaron diferencias significativas en los niveles de cortisol en respuesta al estrés en función de la variancia intrasujeto medida a través del test y retest. Es decir que se comprobó un incremento significativo en la respuesta del cortisol frente a la exposición al estrés en ambos grupos.

Otro dato a tener en cuenta, es que se halló un valor de potencia estadística de 0.361 , por lo que se infiere que la capacidad del presente estudio de encontrar diferencias entre ambos grupos, si la hubiere, sería del 36\%, esto podría llevar a cuestionar si la muestra $(\mathrm{n})$ fuera mayor, los resultados pudieran ser diferentes. Por lo que habría que ampliar el número de la muestra $(n)$, dado que se encontró en la potencia estadística que la capacidad del estudio en una muestra estadísticamente baja es reducida.

Debido a las limitantes mencionadas y resultados dispares de estudios anteriores se considera necesario nuevas investigaciones para llegar a resultados más concluyentes. La necesidad de identificar predictores de vulnerabilidad para futuros desarrollos de patologías relacionadas al estrés y al consumo de alcohol con 
el objeto de prevenir estos trastornos motivó esta investigación. Aunque la hipótesis propuesta no pudo ser confirmada en este estudio, se considera necesario otras investigaciones que podrían incluir otros marcadores, con el objeto de aclarar un tema que presenta resultados contradictorios. 


\section{CONCLUSIÓN}

No existen diferencias significativas en los niveles de cortisol en respuesta al estrés agudo entre participantes con y sin antecedentes de alcoholismo familiar.

Por otro lado, sí existen diferencias significativas en los niveles de cortisol en respuesta al estrés en función de la variancia intrasujeto medida a través del test y retest. 


\section{FORTALEZAS Y DEBILIDADES DEL ESTUDIO}

En el presente estudio se consideran como fortalezas el diseño, el ajuste de la técnica de aplicación del TSST en la población reclutada, el análisis de los datos, la prolijidad de la toma de muestras, el ámbito de desarrollo del estudio.

Como debilidades del estudio se considera no haber chequeado en las mujeres que conformaban la muestra, la fase del ciclo menstrual en que se encontraban, entendiendo que en la fase lútea (progestacional) pueden tener mayor sensibilidad suprarrenal. Otra debilidad es el número de la muestra (n) ya que por el valor de la potencia estadística de 0.361 se infiere que la capacidad de encontrar diferencias entre ambos grupos seria del 36\%, lo que podría llevarnos a pensar que si la muestra fuera mayor, los resultados hubieran podido ser diferentes. 


\section{REFERENCIAS BIBLIOGRÁFICAS}

1. Marquez Lopez Mato A. Psiconeuroinmunoendocrinologia 3. PNIE 3. Capítulo 16, pág. 201. Buenos Aires: Ed Sciens; Sept. 2008.

2. Selye $\mathrm{H}$. The stress concept: past, present and future, en Cooper, $\mathrm{CL}$, stress research: sigues for yhe eighties. Chichester, Ed. John Wiley \& sons; 1986.

3. Mason JW. A review of Psychoendocrine research on the Pituitary-Adrenal Cortical System. Psychosomatic Medicine. Journal of Biobehavioral Medicine. 1968;30:576-607.

4. Rahe RH, Holmes TH. Life change patterns sourrounding illness experience. Journal of psychosomatic research. 1968;11(4):341.

5. Seligman R, Gleser G, Rauh J, Harris L. The effect of earlier parental loss in adolescence. Archives of General Psychiatry. October 1974;31(4).

6. Lazarus, Richard S. Coping Theory and Research: Past, Present and Future. Psychosomatic Medicine. 1993;55:234-247.

7. Levi L. Society, stress and disease. London: Oxford University Press; 1971.

8. Abramson LY, Seligman ME, Teasdale JD. Learned Helplessness in humans: critique and reformulation. Journal of Abnormal Psychology. 1978;87(1):49-74.

9. Lader MH. Society, Stress and Disease. In: Levi L. (editor). London: Oxford University Press. 1971.

10. Medialdea Cruz J. Aspectos de la personalidad y factores estresantes en pilotos de avión: repercusiones en el sistema inmunológico. Universidad Complutense de Madrid, Facultad de Medicina, Departamento de Fisiología [Tesis Doctoral]. Madrid 2002.

11. Kanner AD, Coyne JC, Schaefer C, y Lazarus RS. (1981). Comparison or two modes of stress measurement: Daily hassles and uplifts versus major life events. Journal of Behavioral Medicine. 1981;4:1-39.

12.Sandín B. El estrés: un análisis basado en el papel de los factores sociales. Revista Internacional de Psicología Clínica y de la Salud. 2003;3(1):141-157.

13. Lazarus R, y Folkman S. Stress, appraisal, and coping. Nueva York: Springer; 1984.

14. Marquez Lopez Mato A. Psiconeuroinmunoendocrinologia 3. PNIE 3. Capítulo 6, pág. 84. Buenos Aires: Ed Sciens; Sept 2008. 
15. Blundell L. Physiological Psychology. London: Methuen \& Co. Ltd.; 1975.

16. Davidson RT, Kudler HS, Saunders WB. et al. Symptom and Comorbidity patterns in World War II and Vietnam veterans with posttraumatic stress disorder. Comprehensive Psychiatry. 1990;31:162-170.

17. Khansari DN, Anthony JM, Robert EF. Effects of stress on the immune system. Immuno Today. 1990;11:170-175.

18. Axelrod J, Reisine TD. Stress hormones, their interaccion and regulation. Science. 1984;224:452-459.

19. Bufill E, Carbonell E. Conducta simbolica y neuroplasticidad: ¿un ejemplo de coevolucion gen-cultura? Revisiones en neurociencia. Editor: J. V. SanchezAndres. Rev neurol. 2004;39(1):48-55.

20. Alvano S. Trastornos depresivos y de ansiedad. Aspectos neurobiológicos, clínicos y terapéuticos. Capítulo 1, pág. 27. Buenos Aires: Ed Sciens Bs As; Junio 2010.

21. Munck A, Guyre PM, Holbrook NJ. Physiological functions of glucocorticoides in stress and their relation to pharmacological actions. Endocrinol Rev. 1984;93:9779-9783.

22. Blundell L. Physiological Psychology. London: Methuen \& Co. Ltd.; 1975.

23. Suarez RM. (comp.) Introduction a la psiquiatria. Problemas relacionados con el alcohol y otras sustancias. Tercera edicion. Cap. 21; 576-578. Buenos Aires: Ed. Polemos. 2006.

24. Ventura D. Las cervezas mas antiguas del mundo. BBC Mundo, 27 de febrero de 2012.

25. Monteiro MG. Alcohol y Salud Publica en las Americas. Un caso para la Accion. Washington, D.C.: Biblioteca Sede OPS; 2007.

26. Suarez RM. (comp.) Introduccion a la psiquiatria. Problemas relacionadaso con el alcohol y otras sustancias. Tercera edicion. Cap 21; 572. Buenos Aires: Ed. Polemos; 2006.

27. Obot IS, and Robin R. Gender and drinking problems: Perspectives from low and middle income countries. Geneva, Switzerland: World Health Organization; 2005.

28. Mitchell JM. Alcohol Consumption Induces Endogenous Opioid Release in the Human Orbitofrontal Cortex and Nucleus Accumbens. Sci Transl Med. 2012;4:116ra6.

29. Snell LD. The Biometric Measurement of Alcohol Compsumption. Alcohol Clin Exp Res. 2012;36 (2):332-341. 
30. Delis, F. et al. Loss of Dopamine D2 Receptors Induces Atrophy in the Temporal and Parietal Cortices and the Caudal Thalamus of Ethanol-Consuming Mice. Alcoholism: Clin \& Experim Research, 2011, http://onlinelibrary.wiley.com/loginoptions.

31. Irwin C, Leveritt M, Shum D, Desbrow B. The effects of dehydration, moderate alcohol consumption, and rehydration on cognitive functions. Alcohol. May. 2013;47(3):203-13.

32. http://www.who.int/mediacentre/factsheets/fs349/es/ Organización Mundial de la Salud. Centro de Prensa. Nota descriptiva N³49. Enero de 2015.

33. Boffetta P. Alcohol and Cancer. Lancet Oncol. 2006;7(2):149-156.

34. Jerelles TR. Commentary with regard to the role of alcohol and cofactors in the development of hepatocellular carcinoma. Alcohol Clin Experim Research. 2012;36(4):564-565.

35. Morgan TR, Mandayam S, and Jamal MM. Alcohol and hepatocellular carcinoma. Gastroenterology. 2004;127(5 Suppl 1):S87-96.

36. Allen NE. Moderate alcohol intake and cancer incidence in women. J Natl Cancer Inst. 2009;101(5):296-305.

37. Aeitz HK. Epidemiology and pathophysiology of alcohol and breast cancer: update 2012. Alcohol and Alcoholism. 2012,47(3):204-212.

38. Squeglia LM. Binge drinking differentially affects adolescent male and female brain morphometry. Psychopharmacol. 2012;220:529-539.

39. Sheron N. Projections of alcohol deaths - a wake up call. Lancet. 2011;3779774:1297-1299.

40.WHO. Alcohol use and sexual risk behaviour: a cross-cultural study in eigth countries. Ginebra; 2005.

41. Serebrisky D. Trastornos por sustancias: Alcohol. 1 ed. Fisiología del alcohol y sus efectos sobre la salud, Ciudad Autónoma de Buenos Aires. Sciens. 2014;55(6):56-57.

42. Manzur J. Consumo riesgoso para conducir vehiculos. Ministerio de Salud de la Nacion, Redaccion 23/12/2011;08:48.

43. The World Health Report. Reducing risks, promoting healthy life. Geneva: World Health Organization; 2002.

44. Estudios Nacionales sobre Consumo de Sustancias Psicoactivas realizados por el Observatorio Argentino de Drogas - OAD. Argentina. 2009. [Internet] [acceso 25 de noviembre de 2014]. Disponible en: http://www.observatorio.gov.ar/estudios_consumo_sustancias_psicoactivas.php. 
45. Jernigan DH. The Global Expansion of Alcohol Marketing: Illustrative Case Studies and Recommendations for Action. J Public Health Policy. 1999;20(1):5680.

46. Uhart M, Oswald L, McCaul M, Chong R, Wand G. Hormonal Responses to Psychological Stress and Family History of Alcoholism Neuropsychopharmacology. 2006;31:2255-2263.

47. Dai X, Thavundayil J, Gianoulakis C. Response of the hypothalamic-pituitaryadrenal axis to stress in the absence and presence of ethanol in subjects at high and low risk of alcoholism. Neuropsychopharmacology. Sep. 2002;27(3):442-52.

48.Zimmermann U, Spring K, Kunz-Ebrecht SR, Uhr M, Wittchen HU, Holsboer F. Effect of ethanol on hypothalamic-pituitary-adrenal system response to psychosocial stress in sons of alcohol-dependent fathers. Neuropsychopharmacology. Jun. 2004;29(6):1156-65.

49. Sheehan DV, Lecrubier Y, Sheehan K. The Mini International Neuropsychiatric Interview (M.I.N.I.). The development and validation of a structured diagnostic psychiatric interview for DSM IV and ICD-10. J Clin Psychiatry. 1998;59(suppl 20):22-33.

50. Lecrubier Y, Sheehan D. M.I.N.I. 5.0.0. En: Galli E, Saavedra J (Traductores). M.I.N.I. 5.0.0 Versión en Español / CIE-10 / PERU2003.

51. Sheehan DV, Lecrubier Y, Harnett-Sheehan K, Janavs J, Weiller E, Bonara LI, et al. Reliability and Validity of the M.I.N.I. International Neuropsychiatric Interview (M.I.N.I.): According to the SCID-P. European Psychiatry. 1997;12:232-241.

52. Mann RE, Sobell LC, Sobell MB, and Sobell DP. Reliability of a family tree questionnaire for assessing family history of alcohol problems. Drug and Alcohol Dependence. 1985;15:61-67.

53. Worobec TG, Turner WM, O'Farrell TJ, Cutter HS, Bayog RD, and Tsuang MT. Alcohol use by alcoholics with and without a history of parental alcoholism. Alcoholism. 1990;14:887-892.

54. Kirschbaum C, Pirke K, Hellhammer D. "The Trier Social Stress Test", A tool for investigating Psychobiological Stress Responses in a Laboratory Setting. Neuropsychobiology. 1993;28:76-81

55. Marquez Lopez Mato A. Psiconeuroinmunoendocrinologia 3. PNIE 3. Capítulo 16, pág. 87. Buenos Aires: Ed Sciens; Sept. 2008. 


\section{ANEXOS}

\section{ANEXO 1: CONSENTIMIENTO INFORMADO}

El medico Esteban J. Dávila, en conjunto con la Cátedra de Clínica Psiquiátrica de la Universidad Adventista del Plata está realizando el proyecto de investigación epidemiológica titulado "Respuesta hormonal frente a la exposición de estrés en estudiantes con y sin historia familiar de abuso y/o dependencia de alcohol" con el objetivo de evaluar el efecto de la exposición a una situación de estrés en hormonas relacionadas con el estrés en estudiantes sanos con y sin antecedentes de abuso y dependencia al alcohol de la Universidad Adventista del Plata (UAP).

Yo:

Cl. - DNI. - Pasaporte:

Nacionalidad: Estado civil

Domicilio:

Teléfono: e-mail:

Carrera: Año que cursa:

siendo mayor de 18 años en USO pleno mis facultades mentales y sin que medie coacción ni violencia alguna en completo conocimiento de la naturaleza, forma, duración, propósito, inconvenientes y riesgos relacionados con el estudio que mas abajo índico, declaro mediante la presente:

1.- Haber sido informado de manera objetiva, clara y sencilla, por parte del grupo de Investigadores, coordinados por el Medico Esteban Dávila de todos los aspectos relacionados al proyecto de Investigación epidemiológica titulado "Respuesta hormonal frente a la exposición de estrés en estudiantes con y sin historia familiar de abuso y/o dependencia de alcohol"

2.- Tener conocimiento claro de que el objetivo fundamental del trabajo antes señalado es: evaluar el efecto de la exposición a una situación de estrés en hormonas relacionadas con el estrés en estudiantes sanos con y sin antecedentes de abuso y dependencia al alcohol de la Universidad Adventista del Plata (UAP).

3.- Haber sido informado de que mi participación en el proyecto consiste en responder los test psicológicos que se me entregaran en el momento que los investigadores lo indiquen, ser expuesto a una situación de estrés y dos muestras 
de sangre de $10 \mathrm{cc}$ la cual se me extraerá mediante punción venosa, previa asepsia y antisepsia de la región anterior del antebrazo por una persona capacitada.

4.- Que las muestras sanguíneas que acepto donar así como la información que suministre al equipo de investigadores será utilizada única y exclusivamente para evaluar el efecto de la exposición a una situación de estrés en hormonas relacionadas con el estrés.

5.- Que el equipo de investigadores me ha garantizado confidencialidad relacionada tanto a mi identidad como de cualquier información relativa a mi persona a la que tengan acceso por concepto de mi participación en el proyecto antes mencionado.

6.- Que estoy de acuerdo en el USO, para fines académicos, de los resultados obtenidos en el presente estudio.

7.- Que mi participación en dicho estudio no implica riesgo ni inconveniente alguno para mi salud.

8.- Que cualquier pregunta que yo tenga en relación con este estudio, me será respondida oportunamente por parte del equipo de investigadores antes mencionado con quienes me puedo comunicar por el teléfono (Servicio de Bienestar Mental del Sanatorio Adventista del Plata): 0343-4200244 con el Medico Esteban Davila.

9.- Que bajo ningún concepto se me ha ofrecido ni pretendo recibir algún beneficio de tipo económico producto de los hallazgos que puedan producirse en el referido proyecto de investigación.

10.- Que los resultados de las pruebas me serán entregados oportunamente.

\section{DECLARACIÓN DEL VOLUNTARIO:}

Luego de haber leído, comprendido y recibido las respuestas a mis preguntas con respecto a este formato de consentimiento y por cuanto mi participación en este estudio es totalmente voluntaria acuerdo:

A.- Aceptar las condiciones estipuladas en el mismo y a la vez autorizar al equipo de investigadores a realizar el referido estudio en los test administrados y muestras biológicas de sangre que acepto donar a los fines indicados anteriormente.

B.- Reservarme el derecho de revocar esta autorización así como mi participación en el proyecto, en cualquier momento, sin que ello conlleve algún tipo de consecuencia negativa para mi persona.

Firma del Voluntario:

Firma del Investigador:

Apellido y Nombres: 
Cl. - DNI. - Pasaporte No:

Lugar:

Fecha:

Firma Testigo:

Apellido y Nombre:

Cl. - DNI. - Pasaporte:

Lugar

Fecha

DECLARACIÓN DEL INVESTIGADOR:

Luego de haber explicado detalladamente al voluntario la naturaleza del protocolo mencionado. Certifico mediante la presente que, a mi leal saber, el sujeto que firma este formulario de consentimiento comprende la naturaleza, requerimientos, riesgos y beneficios de la participación en este estudio. Ningún problema de índole médica, de idioma o de instrucción han impedido al sujeto tener una clara comprensión de su compromiso con este estudio.

Medico Esteban J. Dávila

Lugar y Fecha: 
Nombre del paciente

fecha

\begin{tabular}{|c|c|c|}
\hline MODULO I & $\mathrm{SI}$ & NO \\
\hline $\begin{array}{l}\text { 1. En las últimas } 2 \text { semanas, se ha sentido deprimido o decaído la mayor parte del día, casi } \\
\text { todos los días? }\end{array}$ & & \\
\hline $\begin{array}{l}\text { 2. En las últimas } 2 \text { semanas, ha perdido el interés en la mayoría de las cosas o ha disfrutado } \\
\text { menos de las cosas que usualmente le agradaban? }\end{array}$ & & \\
\hline SI CODIFICO SI EN 1 O EN 2 SIGA EL PUNTO 3, SI CODIFICO NO PASE AL MODULO II & & \\
\hline 3. en las últimas 2 semanas, cuando se sentía deprimido o sin interés en las cosas: & & \\
\hline $\begin{array}{l}\text { a. Disminuyo o aumento su apetito caso todos los días? Perdió o gano peso sin } \\
\text { intentarlo? (ej. Variaciones en el último mes de }+-5 \% \text { de su peso corporal o +- } 3.5 \\
\mathrm{~kg} \text { para una persona de } 70 \mathrm{~kg} \text { ) }\end{array}$ & & \\
\hline $\begin{array}{l}\text { b. Tuvo dificultad para dormir casi todas las noches (dificultad para quedarse dormido, } \\
\text { se despertaba a media noche, se despertaba temprano en la mañana o dormía } \\
\text { excesivamente)? }\end{array}$ & & \\
\hline $\begin{array}{l}\text { c. Casi todos los días, hablaba o se movía Ud. más lento de lo usual, o estaba inquieto, } \\
\text { o tenía dificultades para permanecer tranquilo? }\end{array}$ & & \\
\hline d. Casi todos los días se sentía la mayor parte del tiempo fatigado o sin energía? & & \\
\hline e. Casi todos los días se sentía culpable o inútil? & & \\
\hline f. $\quad$ Casi todos los días tenia dificultad para concentrarse o tomar decisiones? & & \\
\hline g. En varias ocasiones, tuvo deseos de hacerse daño, de suicidarse o de estar muerto? & & \\
\hline $\begin{array}{l}\text { SI EL PACIENTE CODIFICA POSITIVO EN CINCO O MAS RESPUESTAS EN LOS PUNTOS } \\
1,2 \text { Y 3, CONTINUE CON 4.a. , DE LO CONTRARIO CONTINUE CON EL MODULO ॥ }\end{array}$ & & \\
\hline $\begin{array}{l}\text { 4. a. en el transcurso de su vida, tuvo otros periodos de } 2 \text { o más semanas, en los que se } \\
\text { sintió deprimido o sin interés en la mayoría de las cosas y que tuvo la mayoría de los } \\
\text { problemas de los que acabamos de hablar? }\end{array}$ & & \\
\hline $\begin{array}{l}\text { b. Ha tenido alguna vez un intervalo de por lo menos } 2 \text { meses, sin depresión o sin falta de } \\
\text { interés en la mayoría de las cosas entre } 2 \text { episodios depresivos? }\end{array}$ & & \\
\hline $\begin{array}{l}\text { MODULO II ( } \rightarrow \text { Significa ir a las casillas diagnósticas, circular NO en cada una y continuar } \\
\text { con el siguiente modulo) }\end{array}$ & & \\
\hline $\begin{array}{l}\text { 1. Este último mes, ha estado usted molesto con pensamientos recurrentes, impulsos o } \\
\text { imágenes no deseadas, desagradables, inapropiadas, intrusas o angustiosas? (ej. La idea de } \\
\text { estar sucio, contaminado o tener gérmenes o miedo de contaminar a otros o temor de hacerle } \\
\text { daño a alguien sin querer, o temor de que actuarían en función de algún impulso, o tiene } \\
\text { temores o supersticiones de ser el responsable de que las cosas vayan mal, o se obsesiona } \\
\text { con pensamientos, imágenes o impulsos sexuales; o acumula o colecciona sin control, o tiene } \\
\text { obsesiones religiosas) (NO incluir preocupaciones excesivas por problemas de la vida } \\
\text { cotidiana. No incluir obsesiones directamente relacionadas con trastornos de la alimentación, } \\
\text { conductas sexuales, problemas patológicos relacionados con el juego, alcohol o abuso de } \\
\text { drogas, porque el paciente pudiera derivar placer de la actividad y pudiera querer evitarla }\end{array}$ & & $\rightarrow 4$ \\
\hline
\end{tabular}


simplemente por las consecuencias negativas)

2. Estos pensamientos volvían a su mente aun cuando trataba de ignorarlos o librarse de ellos?

3. cree Ud. que estos pensamientos son producto de su propia mente y que no le son impuestos desde el exterior?

4. En el pasado mes, ha hecho Ud. algo repetidamente, sin ser capaz de evitarlo, como el lavar o limpiar en exceso, el contar y verificar las cosas una y otra vez o el repetir, el coleccionar, el ordenar las cosas o el realizar otros rituales supersticiosos?

CODIFICO POSITIVO EN 3 Y 4 ?

Reconoce usted que estas ideas obsesivas o actos compulsivos son irracionales, absurdos 0 excesivos?

5. Estas obsesiones o actos compulsivos interfieren de una manera significativa con sus actividades cotidianas, con su trabajo, con sus relaciones sociales, o le ocupan más de una hora diaria?

\section{MODULO III}

1. ha vivido o ha sido testigo de un acontecimiento extremadamente traumático? (ej. Accidentes graves, robo, violación, atentado terrorista, ser tomado de rehén, secuestro, incendio, descubrir un cadáver, muerte súbita de alguien cercano a ud, guerra o catástrofe natural)

2. durante el pasado mes, revivido el evento de una manera angustiosa (ej. Lo ha soñado, ha tenido imágenes vividas, ha reaccionado físicamente o ha tenido memorias intensas)?

3. en el último mes:

a. Ha evitado Ud. pensar en este acontecimiento, o en todo aquello que se lo pudiese recordar?

b. Ha tenido dificultad recordando alguna parte del evento?

c. Ha disminuido su interés en las cosas que le agradaban o en las actividades sociales?

d. Se ha sentido Ud. alejado o distante de otros?

e. Ha notado que sus sentimientos están adormecidos?

f. Ha tenido la impresión de que su vida se va a acortar debido a este trauma o que va a morir antes que otras personas?

CODIFICO POSITIVO EN 3 O MAS RESPUESTAS QUE 3

4. Durante el último mes:

a. Ha tenido Ud. dificultades para dormir?

b. Ha estado particularmente irritable o le daban arranques de coraje?

c. Ha tenido dificultad para concentrarse?

d. Ha estado nervioso o constantemente en alerta?

e. Se ha sobresaltado fácilmente por cualquier cosa?

CODIFICO POSITIVO EN 2 O MAS RESPUESTAS DE 3?

5. En el transcurso de este mes, han interferido estos problemas en su trabajo, en sus actividades sociales, o han sido causa de gran ansiedad?

\section{MODULO IV}

1. a. en más de una ocasión tuvo una crisis o ataques en los cuales se sintió súbitamente ansioso, asustado, incomodo o inquieto, incluso en situaciones en la cual la mayoría de las personas no se sentirían así?

b. Estas crisis o ataques alcanzan su máxima expresión en los primeros 10 minutos?

2. Alguna vez estas crisis o ataques ocurrieron de alguna manera inesperada o espontanea u ocurrieron de forma impredecible o sin provocación?

3. ha tenido una de estas crisis recurrente, seguidas de un periodo de un mes o más en el que temía que otro episodio recurriera o se preocupaba por las consecuencias de la crisis?

4. durante la peor crisis que Ud. pueda recordar:

a. Sentía que su corazón saltaba algunos latidos, latía mas fuerte o más rápido?

b. Sudaba o tenía las manos húmedas?

c. Tenía temblores o sacudidas musculares? 


\begin{tabular}{|c|c|}
\hline d. Sentía la falta de aliento o dificultad para respirar? & \\
\hline e. Tenía sensación de ahogo o un nudo en la garganta? & \\
\hline f. Notaba dolor o molestia en el pecho? & \\
\hline g. Tenía nauseas, molestias en el estómago o diarreas repentinas? & \\
\hline h. Se sentía mareado, inestable, aturdido o a punto de desvanecer? & \\
\hline $\begin{array}{l}\text { i. Le parecía que las cosas a su alrededor eran irreales, extrañas, indiferentes, o no le } \\
\text { parecían familiares, o se sintió fuera o separado de su cuerpo o de partes de su } \\
\text { cuerpo? }\end{array}$ & \\
\hline j. Tenía miedo de perder el control o volverse loco? & \\
\hline k. Tenía miedo de que se estuviera muriendo? & \\
\hline I. Tenía alguna parte de su cuerpo adormecida o con hormigueos? & \\
\hline m. Tenía sofocaciones o escalofríos? & \\
\hline 5. codifico SI en 3 y en por lo menos 4 de 4 ? ( trastorno de angustia) & \\
\hline 6. si $5=\mathrm{NO}$, codifico $\mathrm{SI}$ en alguna respuesta de 4 ? & \\
\hline $\begin{array}{l}\text { 7. en el pasado mes, tuvo estas crisis en varias ocasiones ( } 2 \text { o más), seguidas de miedo } \\
\text { persistente a tener otra? }\end{array}$ & \\
\hline MODULO V & \\
\hline $\begin{array}{l}(\rightarrow \text { significa ir a las casillas diagnósticas, circular NO en cada una y continuar con el } \\
\text { siguiente modulo). }\end{array}$ & \\
\hline $\begin{array}{l}\text { 1. en el pasado mes, tuvo miedo o sintió vergüenza de que lo estén observando, de ser el } \\
\text { centro de atención o temió una humillación? Incluyendo cosas como el hablar en público, } \\
\text { comer en público o con otros, el escribir mientras alguien le mira o el participar en situaciones } \\
\text { sociales? }\end{array}$ & $\rightarrow$ \\
\hline 2. piensa Ud. que este miedo es excesivo o irracional? & $\rightarrow$ \\
\hline 3. teme tanto estas situaciones sociales que las evita o sufre a través de ellas? & $\rightarrow$ \\
\hline $\begin{array}{l}\text { 4. este miedo interfiere en su trabajo normal o en el desempeño de sus actividades sociales o } \\
\text { es la causa de intensa molestia? }\end{array}$ & \\
\hline MODULO VI & \\
\hline $\begin{array}{l}(\rightarrow \text { significa ir a las casillas diagnósticas, circular NO en cada una y continuar con el siguiente } \\
\text { modulo). }\end{array}$ & \\
\hline $\begin{array}{l}\text { 1. a. Se ha sentido excesivamente preocupado o ansioso debido a varias cosas durante los } \\
\text { últimos } 6 \text { meses? }\end{array}$ & $\rightarrow$ \\
\hline b. Se presentan estas preocupaciones casi todos los días? & $\rightarrow$ \\
\hline $\begin{array}{l}\text { Codificar SI, si la ansiedad de paciente es restringida exclusivamente, o mejor explicada por } \\
\text { cualquiera de los trastornos previamente discutidos. }\end{array}$ & $\rightarrow$ \\
\hline $\begin{array}{l}\text { 2. Le resulta difícil controlar estas preocupaciones o interfieren para concentrarse en lo que } \\
\text { hace? }\end{array}$ & $\rightarrow$ \\
\hline $\begin{array}{l}\text { 3. codifique NO si los síntomas se limitan a rasgos de cualquiera de los trastornos previamente } \\
\text { explorados. } \\
\text { En los últimos } 6 \text { meses cuando estaba ansioso, casi todo el tiempo: }\end{array}$ & \\
\hline a. Se sentía inquieto, intranquilo o agitado? & \\
\hline b. Se sentía tenso? & \\
\hline c. Se sentía cansado, flojo o se agotaba fácilmente? & \\
\hline d. Tenía dificultad para concentrarse, o nota que la mente se le quedaba en blanco? & \\
\hline e. Se sentía irritable? & \\
\hline $\begin{array}{l}\text { f. Tenía dificultad durmiendo (dificultad para quedarse dormido, se despertaba a media } \\
\text { noche o demasiado temprano, o dormía en exceso)? }\end{array}$ & \\
\hline Codifico SI en 3 o más respuestas de 3 ? & \\
\hline & \\
\hline
\end{tabular}


Participante $\mathrm{N}^{\circ}$

Fecha

\section{CUESTIONARIO DEL ÁRBOL FAMILIAR}

Instrucciones:

Con cada ítem desarrollado más abajo se quiere clasificar el comportamiento de los miembros de la familia que consumen alcohol en cinco categorías. Solo se deben incluir parientes sanguíneos, no se incluyen aquellos que son adoptados o medios hermanos 0 hermanastros.

\section{Clasifique cada pariente usando uno de los siguientes cinco códigos:}

1- Nunca consumió bebidas alcohólicas (abstemio toda la vida)

2- Bebedor social : bebe moderadamente y no se le conoce que haya tenido problemas por el consumo de alcohol

3- Posible problema por consumo de alcohol: una persona que Ud. cree o le contaron que podría tener o tuvo problemas por beber alcohol, pero que no sabe con certeza si es así.

4- Definitivamente tiene problemas por beber alcohol: aquí se incluyen solo las personas que sabe con certeza que han recibido tratamiento por sus problemas con el alcohol (inclusive si es miembro regular de alcohólicos anónimos) o aquellas personas que se sabe han experimentado consecuencias negativas varias por causa del alcohol.

5- No tiene relación con alcohol: solo aplicable a hermanos y hermanas.

6- No sabe / No recuerda.

\section{Abuela materna Abuelo materno Abuela paterna Abuelo paterno}

$1-$ 2

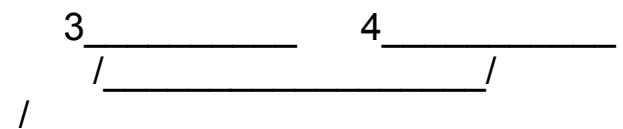

Padre

\section{5}

6

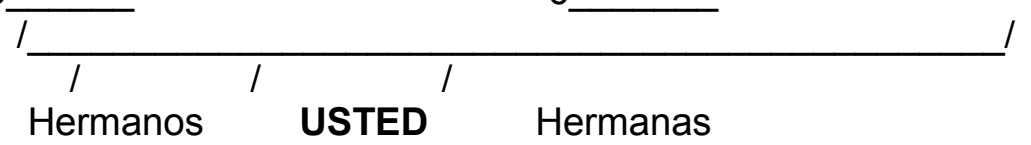

7 8 9 10

11 12 13 14 


\section{ANEXO 4: T.S.S.T. (TRIER SOCIAL STRESS TEST)}

\section{Procedimiento:}

EI TSST consiste en el desarrollo de varios pasos, en primer lugar el individuo llega al laboratorio es recibido por un encargado o recepcionista y reposa 10 minutos en un salón tranquilo (S 1) luego de lo cual se le extraen 8-10 ml de sangre (muestra pretest), posteriormente se lo lleva a otro salón (S 2) donde se encuentra un tribunal compuesto por 4 personas, una cámara filmadora, un micrófono multidireccional y una luz directa a un sector donde se ubicara la persona, allí el encargado le explica al participante que deberá preparar un discurso con el cual deberá convencer a este tribunal que él es la persona más adecuada para ingresar a la carrera de medicina de esta universidad, esto será filmado, grabado y medido por un sistema para detectar señales de tensión nerviosa y que los miembros del tribunal son expertos en detectar señales de tensión. Luego de la explicación si no hay preguntas se lo lleva nuevamente al S1 y se le dan 10 minutos para preparar su discurso, se le proveen lápiz y papel para anotaciones pero se le aclara que no podrá llevarlos a la exposición. Al cumplirse el tiempo se lo lleva nuevamente al S 2 donde el presidente del tribunal le pide el nombre y le dice que comience con su discurso, se lo deja hablar durante 5 minutos, mientras el tribunal lo observa, pueden hacer anotaciones, si el participante termina su discurso antes de los 5 minutos el presidente del tribunal puede hacer preguntas hasta que se cumpla el tiempo. Seguidamente se le solicita que realice un cálculo matemático que presenta dificultad como por ejemplo descender en pasos de 13 números hasta llegar a 0 , lo más rápidamente posible desde el número 2011, cada vez que la persona se equivoque el presidente del tribunal dice "error" y el participante debe comenzar de nuevo, esto durante 5 minutos, luego de lo cual se le dice "suficiente" y se lo retira del salón. Al salir es recibido por el encargado quien se ocupa de explicar al participante que lo que acaba de hacer es una simulación, que no se ha filmado ni grabado su discurso y que esto era para provocar un estado de tensión para el 
estudio, se espera unos 10 minutos y se le extrae nuevamente sangre (muestra post test).

En el desarrollo del estudio cada sujeto empleo aproximadamente 60 minutos en el laboratorio. De ese tiempo, aproximadamente 20 minutos fueron usados en el protocolo de tensión psicológico real, el tiempo restante fue empleado en la introducción al TSST, toma de muestras biológicas y preguntas.

\section{Recepcionista:}

Es quien recibe al participante y es responsable de la instrucción y de la coordinación oportuna del mismo. Lleva un cronometro para las tomas de las muestras y el tiempo de cada paso que se realizara.

Al recibir al sujeto, le hace preguntas por limitaciones relativas a la salud o el estímulo posible del eje HPA del momento (enfermedades, actividades físicas apenas antes de llegada, cigarrillos fumados, y medicaciones tomadas). Luego lo lleva al salón $B$ le da las explicaciones y posteriormente lo vuelve al salón A para el descanso y la preparación de su discurso.

Antes y durante del periodo de descanso no se debe dar información detallada del procedimiento exacto del experimento; ya que el participante puede anticipar exactamente qué viene, y esto podría tener un efecto estimulante sobre el eje de HPA. Si hay algunas preguntas sobre el contenido específico del experimento, el recepcionista debe contestar con una declaración algo general sobre una situación de la tensión psicológica y referir a una introducción posterior para los detalles. Después del tiempo de preparación lo lleva a realizar el trabajo de tensión. Con esto, el trabajo del recepcionista concluye. Generalmente espera al siguiente participante, con la recepción e introducción del test.

\section{Comité:}

El comité tiene contacto dos veces con el participante, durante la introducción y durante la fase real de la tensión. Durante la introducción el único deber del comité es estar presente. El participante se supone que tiene que tener una impresión de lo que será el experimento en el que estará introducido. 
El aspecto principal del TSST es el rol-play, y para esto es importante que cada uno juegue su papel lo mejor posible. Como el comité tiene que decidir sobre la aceptación de un aspirante para una posición específica, la idea es por lo tanto dejar la impresión de que no quede ninguna duda sobre la seriedad de este esfuerzo. Además, se pretende que el TSST sea una situación de tensión psicológica; para eso es importante mantener un humor serio, se debe evitar hablar de la situación como tal.

Está claro que una entrevista de admisión verdadera nunca ocurriría como esto en la vida real y que el TSST puede solamente ser un compromiso, sin embargo, eso debe solamente ser discutido a la hora de la introducción o del posttest, pero no durante la tarea del discurso. Por lo tanto se recomienda que durante la introducción dado por el recepcionista, ningunos de los miembros del comité hablan o ríen. Si por algún motivo el recepcionista se dirige al comité, ellos deberían contestar solamente con un saludo cortés. Si es necesario, debe aclararse que cualquier pregunta del participante debe dirigirse al recepcionista y no al comité.

La tarea real del comité comienza cuando el participante entra a la sala diez minutos más adelante de entregar su discurso. En ese momento el presidente del comité debe encender la videocámara a mano o por control remoto. Él abre la sesión con las siguientes palabras; "Ubíquese por favor sobre la alfombra que se encuentra en el centro de la sala, diga su nombre completo y comience su discurso". Simultáneamente, el miembro del comité sentado a la izquierda acomoda el micrófono multidireccional que se encuentra en el escritorio, aunque solamente como trampa, este gesto es de gran importancia a la luz del contexto circunstancial. Además todos los miembros del comité deben buscar el contacto visual con el participante durante el discurso; el hecho que todas las personas presentes están prestando su atención, refuerza más la seriedad de la situación para el mismo. Por supuesto, allí no debe haber ninguna risa durante el discurso.

Solamente el presidente debe dirigirse al participante directamente, para poder evitar problemas de coordinación entre los miembros del comité.

Se debe dejar hablar al participante los primeros tres minutos. En la mayoría de los casos terminara el discurso incluso antes de los tres minutos. Se debe dejar 
formular elaboraciones adicionales. En todo caso, debe haber una pausa. Después de que la pausa supera los veinte segundos pueda alertar al participante el tiempo restante, como por ejemplo "Usted todavía tiene tiempo, continúe por favor... ". Si no dice nada por otros diez segundos, el presidente del comité debe hacer preguntas hasta que se cumpla el tiempo.

La redacción de estas preguntas se deja a la discreción del presidente; más o menos orientada a las declaraciones anteriores del participante. Las preguntas típicas en este contexto son: ¿Por qué piensa usted que es el mejor aspirante para esta posición? ¿Qué otras experiencias ha tenido en esta área? ¿Qué de sus estudios identifica una aptitud y una motivación especial para esta posición? ¿Donde más se ha presentado para el ingreso universitario? ¿Por qué? ¿Qué haría usted, si no tiene éxito con esto?

En casos raros el participante logra o desea hablar los cinco minutos completos. En ese caso se deja a la discreción del presidente si quiere intervenir entre el tercer y quinto minuto para hacer preguntas, o si se le permite continuar. Esto también va a depender en qué está siendo dicho por el participante. Por ejemplo, no sería apropiado que el aspirante hable con gran detalle sobre las lecciones específicas que pudo haber aprendido en un curso de la universidad o en otra parte.

Algunos participantes usan sus conocimientos académicos para distraer de su propia persona. En ese caso el presidente debe intervenir, diciendo por ejemplo: "Le creemos a usted que sabe sobre determinado tema, pero nos sería de mayor interés descubrir el motivo por el cual usted es un buen candidato para el ingreso en esta institución."

Después de los cinco minutos, el presidente del comité debe explicar la segunda parte del protocolo de tensión. Para evitar incomodar al participante, es muy importante ser claro que ésta sección de la tarea es una segunda parte que no tiene nada que ver con el discurso del aplicante. Una transición típica seria decir algo como: "muchas gracias, eso es suficiente por ahora. Ahora queremos pedirle que trabaje en una segunda tarea. Ésta es sobre un cálculo aritmético. Le pedimos que cuente al revés hasta llegar a cero en pasos de 13, comenzando en 2011, y 
hacerlo tan rápido y correctamente como sea posible. Si usted calcula mal, se le avisara y comenzara otra vez en 2011. ¿Usted tiene preguntas sobre esto? ... Comience por favor."

Se recomienda utilizar números primos para substraer, porque éstos hacen el trabajo más difícil. Las hojas del protocolo con todos los números intermedios estarán disponibles así los miembros del comité no tienen que calcular.

Si el participante calcula mal, el presidente del comité responderá con una frase estandarizada: "Error. 2011." hasta el final del período de prueba. Además el comité debe observar el número de errores y el número que el participante alcanzó como medida de evaluación.

Al final de la tarea el presidente del comité debe agradecer al participante por su participación y pedir que él/ella vaya a la habitación vecina para concluir. Con esto, el rol del comité se concluye en el TSST. 
ANEXO 5: TABLAS DE RESULTADOS DEL SPSS

Tabla de frecuencia

\begin{tabular}{|c|c|c|c|c|c|}
\hline & & Frecuencia & Porcentaje & $\begin{array}{l}\text { Porcentaje } \\
\text { válido }\end{array}$ & $\begin{array}{l}\text { Porcentaje } \\
\text { acumulado }\end{array}$ \\
\hline \multirow[t]{14}{*}{ Válidos } & 18 & $\overline{1}$ & 1,3 & 1,3 & 1,3 \\
\hline & 19 & 9 & 11,8 & 11,8 & 13,2 \\
\hline & 20 & 17 & 22,4 & 22,4 & 35,5 \\
\hline & 21 & 10 & 13,2 & 13,2 & 48,7 \\
\hline & 22 & 12 & 15,8 & 15,8 & 64,5 \\
\hline & 23 & 11 & 14,5 & 14,5 & 78,9 \\
\hline & 24 & 6 & 7,9 & 7,9 & 86,8 \\
\hline & 25 & 4 & 5,3 & 5,3 & 92,1 \\
\hline & 26 & 2 & 2,6 & 2,6 & 94,7 \\
\hline & 28 & 1 & 1,3 & 1,3 & 96,1 \\
\hline & 30 & 1 & 1,3 & 1,3 & 97,4 \\
\hline & 48 & 1 & 1,3 & 1,3 & 98,7 \\
\hline & 49 & 1 & 1,3 & 1,3 & 100,0 \\
\hline & Total & 76 & 100,0 & 100,0 & \\
\hline
\end{tabular}

\begin{tabular}{|c|c|c|c|c|c|}
\hline & & Frecuencia & Porcentaje & $\begin{array}{l}\text { Porcentaje } \\
\text { válido }\end{array}$ & $\begin{array}{l}\text { Porcentaje } \\
\text { acumulado }\end{array}$ \\
\hline \multirow{18}{*}{ Válidos } & argentina & 37 & 48,7 & 48,7 & 48,7 \\
\hline & brasileña & 4 & 5,3 & 5,3 & 53,9 \\
\hline & brasilero & 7 & 9,2 & 9,2 & 63,2 \\
\hline & chilena & 5 & 6,6 & 6,6 & 69,7 \\
\hline & chileno & 7 & 9,2 & 9,2 & 78,9 \\
\hline & colombiana & 1 & 1,3 & 1,3 & 80,3 \\
\hline & colombiano & 3 & 3,9 & 3,9 & 84,2 \\
\hline & ecuatoriana & 1 & 1,3 & 1,3 & 85,5 \\
\hline & filipina & 1 & 1,3 & 1,3 & 86,8 \\
\hline & mexicano & 1 & 1,3 & 1,3 & 88,2 \\
\hline & noruega & 1 & 1,3 & 1,3 & 89,5 \\
\hline & panameño & 1 & 1,3 & 1,3 & 90,8 \\
\hline & paragayo & 1 & 1,3 & 1,3 & 92,1 \\
\hline & paraguaya & 1 & 1,3 & 1,3 & 93,4 \\
\hline & peruana & 2 & 2,6 & 2,6 & 96,1 \\
\hline & peruano & 2 & 2,6 & 2,6 & 98,7 \\
\hline & ucraniana & 1 & 1,3 & 1,3 & 100,0 \\
\hline & Total & 76 & 100,0 & 100,0 & \\
\hline
\end{tabular}


es tado civi

\begin{tabular}{|cl|r|r|r|r|}
\hline & Frecuencia & Porcentaje & \multicolumn{1}{|c|}{$\begin{array}{c}\text { Porcentaje } \\
\text { válido }\end{array}$} & $\begin{array}{c}\text { Porcentaje } \\
\text { acumulado }\end{array}$ \\
\hline Válidos & casada & 3 & 3,9 & 3,9 & 3,9 \\
& divorciada & 1 & 1,3 & 1,3 & 5,3 \\
nc & 1 & 1,3 & 1,3 & 6,6 \\
soltera & 42 & 55,3 & 55,3 & 61,8 \\
soltero & 29 & 38,2 & 38,2 & 100,0 \\
Total & 76 & 100,0 & 100,0 & \\
\hline
\end{tabular}

religion

\begin{tabular}{|ll|r|r|r|r|}
\hline & & & $\begin{array}{c}\text { Porcentaje } \\
\text { válido }\end{array}$ & $\begin{array}{r}\text { Porcentaje } \\
\text { acumulado }\end{array}$ \\
\hline Válidos & adv & 59 & 77,6 & 77,6 & 77,6 \\
& bautista & 1 & 1,3 & 1,3 & 78,9 \\
catolica & 8 & 10,5 & 10,5 & 89,5 \\
catolico & 2 & 2,6 & 2,6 & 92,1 \\
cristiana evangelica & 1 & 1,3 & 1,3 & 93,4 \\
mormona & 1 & 1,3 & 1,3 & 94,7 \\
nc & 4 & 5,3 & 5,3 & 100,0 \\
Total & 76 & 100,0 & 100,0 & \\
\hline
\end{tabular}

carrera

\begin{tabular}{|l|r|r|r|r|}
\hline & Frecuencia & Porcentaje & $\begin{array}{c}\text { Porcentaje } \\
\text { vál ido }\end{array}$ & $\begin{array}{c}\text { Porcentaje } \\
\text { acumulado }\end{array}$ \\
\hline Válidos med & 76 & 100,0 & 100,0 & 100,0 \\
\hline
\end{tabular}

año

\begin{tabular}{|ll|r|r|r|r|}
\hline & Frecuencia & Porcentaje & $\begin{array}{c}\text { Porcentaje } \\
\text { válido }\end{array}$ & $\begin{array}{c}\text { Porcentaje } \\
\text { acumulado }\end{array}$ \\
\hline Válidos & 1 y 2 & 4 & 5,3 & 5,3 & 5,3 \\
& 2 & 11 & 14,5 & 14,5 & 19,7 \\
3 & 28 & 36,8 & 36,8 & 56,6 \\
4 & 13 & 17,1 & 17,1 & 73,7 \\
5 & 20 & 26,3 & 26,3 & 100,0 \\
Total & 76 & 100,0 & 100,0 & \\
\hline
\end{tabular}


tra baja

\begin{tabular}{|rl|r|r|r|r|}
\hline & Frecuencia & Porcentaje & $\begin{array}{c}\text { Porcentaje } \\
\text { válido }\end{array}$ & $\begin{array}{c}\text { Porcentaje } \\
\text { acumulado }\end{array}$ \\
\hline Válidos & nc & 21 & 27,6 & 27,6 & 27,6 \\
& no & 50 & 65,8 & 65,8 & 93,4 \\
si & 5 & 6,6 & 6,6 & 100,0 \\
& Total & 76 & 100,0 & 100,0 & \\
\hline
\end{tabular}

hijos

\begin{tabular}{|rl|r|r|r|r|}
\hline & Frecuencia & Porcentaje & $\begin{array}{c}\text { Porcentaje } \\
\text { vál ido }\end{array}$ & $\begin{array}{c}\text { Porcentaje } \\
\text { acumulado }\end{array}$ \\
\hline Válidos & 2 & 2 & 2,6 & 2,6 & 2,6 \\
& nc & 41 & 53,9 & 53,9 & 56,6 \\
& no & 32 & 42,1 & 42,1 & 98,7 \\
si 3 & 1 & 1,3 & 1,3 & 100,0 \\
& Total & 76 & 100,0 & 100,0 & \\
\hline
\end{tabular}

antec

\begin{tabular}{|ll|r|r|r|r|}
\hline & Frecuencia & Porcentaje & $\begin{array}{c}\text { Porcentaje } \\
\text { válido }\end{array}$ & $\begin{array}{r}\text { Porcentaje } \\
\text { acumulado }\end{array}$ \\
\hline Válidos & 3 hermanos & 1 & 1,3 & 1,3 & 1,3 \\
& abuelo mat & 15 & 19,7 & 19,7 & 21,1 \\
abuelo pat & 10 & 13,2 & 13,2 & 34,2 \\
hermano & 2 & 2,6 & 2,6 & 36,8 \\
madre & 1 & 1,3 & 1,3 & 38,2 \\
no & 41 & 53,9 & 53,9 & 92,1 \\
padre & 6 & 7,9 & 7,9 & 100,0 \\
Total & 76 & 100,0 & 100,0 & \\
\hline
\end{tabular}

\begin{tabular}{|ll|r|r|r|r|}
\hline \multicolumn{7}{|c|}{ antec } \\
\hline & & Frecuencia & Porcentaje & $\begin{array}{c}\text { Porcentaje } \\
\text { válido }\end{array}$ & $\begin{array}{c}\text { Porcentaje } \\
\text { acumulado }\end{array}$ \\
\hline Válidos & 71 & 93,4 & 93,4 & 93,4 \\
& abuelo mat & 1 & 1,3 & 1,3 & 94,7 \\
& abuelo pat & 1 & 1,3 & 1,3 & 96,1 \\
& hermano & 3 & 3,9 & 3,9 & 100,0 \\
& Total & 76 & 100,0 & 100,0 & \\
\hline
\end{tabular}


PARTICIPO

\begin{tabular}{|rl|r|r|r|r|}
\hline & Frecuencia & Porcentaje & \multicolumn{1}{c|}{$\begin{array}{c}\text { Porcentaje } \\
\text { válido }\end{array}$} & $\begin{array}{c}\text { Porcentaje } \\
\text { acumulado }\end{array}$ \\
\hline Válidos & NO & 1 & 1,3 & 1,3 & 1,3 \\
& SI & 75 & 98,7 & 98,7 & 100,0 \\
& Total & 76 & 100,0 & 100,0 & \\
\hline
\end{tabular}

MOTIVO

\begin{tabular}{|ll|r|r|r|r|}
\hline & & & Porcentaje & Porcentaje \\
& & Frecuencia & Porcentaje & $\begin{array}{c}\text { vacumulado } \\
\text { acuma }\end{array}$ \\
\hline Válidos & 75 & 98,7 & 98,7 & 98,7 \\
& & 1 & 1,3 & 1,3 & 100,0 \\
& no se lo pudo ubicar & 76 & 100,0 & 100,0 & \\
\hline & Total & 76 &
\end{tabular}

Grupo Antecedente de Alcoholismo

\begin{tabular}{|rl|r|r|r|r|}
\hline & & & & \multicolumn{1}{c|}{$\begin{array}{c}\text { Porcentaje } \\
\text { válido }\end{array}$} & $\begin{array}{c}\text { Porcentaje } \\
\text { acumulado }\end{array}$ \\
\hline Válidos & 0 & 41 & 53,9 & 53,9 & 53,9 \\
& 1 & 35 & 46,1 & 46,1 & 100,0 \\
& Total & 76 & 100,0 & 100,0 & \\
\hline
\end{tabular}

Tabla comparativa entre las variables "con y sin antecedentes de alcoholismo" vs "el nivel de cortisol basal y postest"

\begin{tabular}{|c|c|c|c|c|}
\hline \multicolumn{5}{|c|}{ Estadísticos } \\
\hline & & & cortisol basal & $\begin{array}{l}\text { cortisol } \\
\text { post test }\end{array}$ \\
\hline \multirow[t]{4}{*}{0} & $\mathrm{~N}$ & Válidos & 39 & 39 \\
\hline & & Perdidos & 2 & 2 \\
\hline & & & 17,5641 & 22,5395 \\
\hline & & & 5,41078 & 6,12121 \\
\hline \multirow[t]{4}{*}{1} & $\mathrm{~N}$ & Válidos & 34 & 34 \\
\hline & & Perdidos & 1 & 1 \\
\hline & & & 14,7588 & 21,6591 \\
\hline & & & 5,82238 & 5,49514 \\
\hline
\end{tabular}




\section{Resultados que responden al OBJETIVO GENERAL:}

\section{ANOVA de medidas repetidas}

Contra ste s multivaria dods

\begin{tabular}{|c|c|c|c|c|c|c|}
\hline Efecto & & Valor & $\mathrm{F}$ & $\begin{array}{c}\text { GI de la } \\
\text { hipótes is }\end{array}$ & GI del error & Significación \\
\hline \multirow[t]{4}{*}{ Tiempo } & Traza de Pillai & ,489 & $68,038^{a}$ & 1,000 & 71,000 & ,000 \\
\hline & Lambda de Wilks &, 511 & $68,038^{a}$ & 1,000 & 71,000 &, 000 \\
\hline & Traza de Hotelling & ,958 & $68,038^{a}$ & 1,000 & 71,000 &, 000 \\
\hline & Raíz mayor de Roy & ,958 & $68,038^{a}$ & 1,000 & 71,000 &, 000 \\
\hline \multirow{4}{*}{$\begin{array}{l}\text { Tiempo * } \\
\text { GrupoAntecedentede } \\
\text { Alcoholismo }\end{array}$} & Traza de Pillai & ,025 & $1,788^{\mathrm{a}}$ & 1,000 & 71,000 & , 185 \\
\hline & Lambda de Wilks & ,975 & $1,788^{a}$ & 1,000 & 71,000 & 185 \\
\hline & Traza de Hotelling & 025 & $1,788^{\mathrm{a}}$ & 1,000 & 71,000 & , 185 \\
\hline & Raíz mayor de Roy & ,025 & $1,788^{\mathrm{a}}$ & 1,000 & 71,000 & ,185 \\
\hline
\end{tabular}

a. Estadístico exacto

b.

Diseño: Intersección+GrupoAntecedentedeAlcoholis mo

Diseño intra sujetos: Tiempo

\section{Prueba de esfericidad de Mauchly(b)}

Medida: MEASURE 1

\begin{tabular}{|c|c|c|c|c|c|c|c|}
\hline $\begin{array}{l}\text { Efecto intra- } \\
\text { sujetos }\end{array}$ & $\begin{array}{c}\text { W de } \\
\text { Mauchly }\end{array}$ & $\begin{array}{c}\text { Chi- } \\
\text { cuadrado } \\
\text { aprox. }\end{array}$ & $\mathrm{gl}$ & Significación & \multicolumn{3}{|c|}{ Epsilon(a) } \\
\hline & $\begin{array}{c}\text { Greenhouse } \\
\text {-Geisser }\end{array}$ & $\begin{array}{l}\text { Huynh- } \\
\text { Feldt }\end{array}$ & $\begin{array}{l}\text { Límite- } \\
\text { inferior }\end{array}$ & $\begin{array}{c}\text { Greenhouse- } \\
\text { Geisser }\end{array}$ & $\begin{array}{l}\text { Huynh } \\
\text {-Feldt }\end{array}$ & $\begin{array}{l}\text { Límite- } \\
\text { inferior }\end{array}$ & $\begin{array}{c}\text { Greenhouse } \\
\text {-Geisser }\end{array}$ \\
\hline Tiempo & 1,000 & ,000 & 0 & & 1,000 & 1,000 & 1,000 \\
\hline
\end{tabular}

Contrasta la hipótesis nula de que la matriz de covarianza error de las variables dependientes transformadas es proporcional a una matriz identidad. 


\begin{tabular}{|c|c|c|c|c|c|c|}
\hline Fuente & & $\begin{array}{c}\text { Suma de } \\
\text { cuadrados } \\
\text { tipo III }\end{array}$ & gl & $\begin{array}{c}\text { Media } \\
\text { cuadráti } \\
\text { ca } \\
\end{array}$ & $\mathrm{F}$ & Significación \\
\hline \multirow[t]{4}{*}{ Tiempo } & $\begin{array}{l}\text { Esfericidad } \\
\text { asumida }\end{array}$ & 1280,877 & 1 & $\begin{array}{r}1280,87 \\
7\end{array}$ & 68,038 & ,000 \\
\hline & $\begin{array}{l}\text { Greenhouse- } \\
\text { Geisser }\end{array}$ & 1280,877 & 1,000 & $\begin{array}{r}1280,87 \\
7\end{array}$ & 68,038 & ,000 \\
\hline & Huynh-Feldt & 1280,877 & 1,000 & $\begin{array}{r}1280,87 \\
7\end{array}$ & 68,038 & ,000 \\
\hline & $\begin{array}{l}\text { Límite- } \\
\text { inferior }\end{array}$ & 1280,877 & 1,000 & $\begin{array}{r}1280,87 \\
7\end{array}$ & 68,038 & 000 \\
\hline \multirow{4}{*}{$\begin{array}{l}\text { Tiempo* Grupo } \\
\text { Antecedente de } \\
\text { Alcoholismo }\end{array}$} & $\begin{array}{l}\text { Esfericidad } \\
\text { asumida }\end{array}$ & 33,652 & 1 & 33,652 & 1,788 & , 185 \\
\hline & $\begin{array}{l}\text { Greenhouse- } \\
\text { Geisser }\end{array}$ & 33,652 & 1,000 & 33,652 & 1,788 & , 185 \\
\hline & Huynh-Feldt & 33,652 & 1,000 & 33,652 & 1,788 & , 185 \\
\hline & $\begin{array}{l}\text { Límite- } \\
\text { inferior }\end{array}$ & 33,652 & 1,000 & 33,652 & 1,788 & 185, \\
\hline \multirow[t]{4}{*}{ Error (Tiempo) } & $\begin{array}{l}\text { Esfericidad } \\
\text { asumida }\end{array}$ & 1336,644 & 71 & 18,826 & & \\
\hline & $\begin{array}{l}\text { Greenhouse- } \\
\text { Geisser }\end{array}$ & 1336,644 & 71,000 & 18,826 & & \\
\hline & Huynh-Feldt & 1336,644 & 71,000 & 18,826 & & \\
\hline & $\begin{array}{l}\text { Límite- } \\
\text { inferior }\end{array}$ & 1336,644 & 71,000 & 18,826 & & \\
\hline
\end{tabular}

a Puede usarse para corregir los grados de libertad en las pruebas de significación promediadas. Las pruebas corregidas se muestran en la tabla Pruebas de los efectos inter-sujetos.

b Diseño: Intersección + Grupo Antecedente de Alcoholismo

Diseño intra sujetos: Tiempo

\section{Pruebas de efectos intra-sujetos}

Medida: MEASURE_1

\section{Pruebas de contrastes intra-sujetos}

Medida: MEASURE_1

\begin{tabular}{|ll|r|r|r|r|r|}
\hline Fuente & Tiempo & $\begin{array}{c}\text { Suma de } \\
\text { cuadrados } \\
\text { tipo III }\end{array}$ & gl & $\begin{array}{c}\text { Media } \\
\text { cuadrática }\end{array}$ & \multicolumn{1}{c|}{$\mathrm{F}$} & Significación \\
\hline Tiempo & Lineal & 1280,877 & 1 & 1280,877 & 68,038 &, 000 \\
\hline Tiempo * & Lineal & 33,652 & 1 & 33,652 & 1,788 &, 185 \\
\hline Error(Tiempo) & Lineal & 1336,644 & 71 & 18,826 & & \\
\hline
\end{tabular}


Pruebas de los efectos inter-sujetos

Medida: MEASURE_1

Variable transformad̄a: Promedio

\begin{tabular}{|l|r|r|r|r|r|}
\hline & \multicolumn{1}{c|}{$\begin{array}{c}\text { Suma de } \\
\text { cuadrados } \\
\text { tipo III }\end{array}$} & gl & \multicolumn{1}{c|}{$\begin{array}{c}\text { Media } \\
\text { cuadrática }\end{array}$} & \multicolumn{1}{c|}{ F } & Significación \\
\hline Intersección & 53181,180 & 1 & 53181,180 & 1139,063 &, 000 \\
Grupo Antecedente de & 123,373 & 1 & 123,373 & 2,642 &, 108 \\
Alcoholismo & 3314,886 & 71 & 46,689 & & \\
Error & & & & \\
\hline
\end{tabular}

\section{Medias marginales estimadas de MEASURE_1}

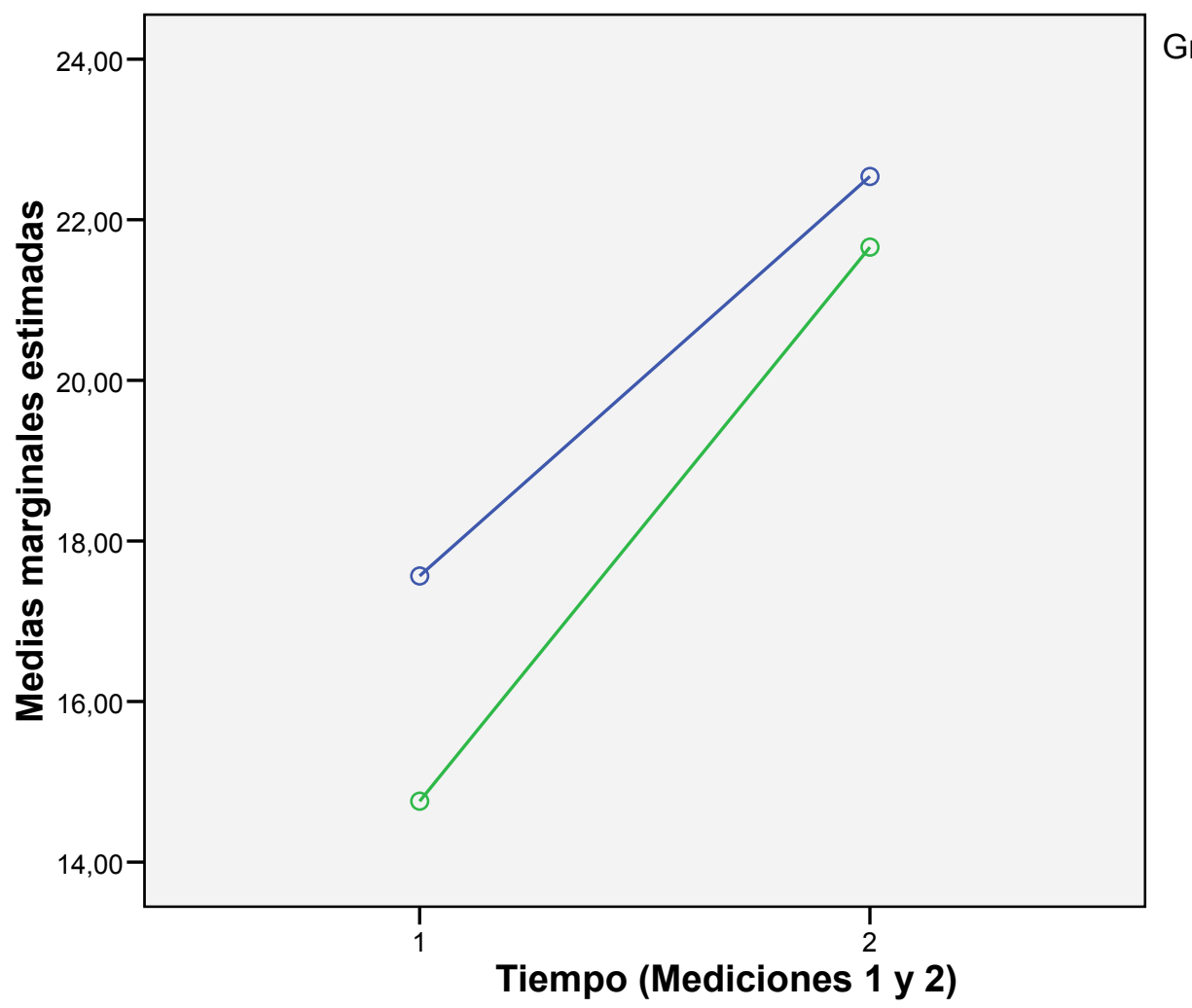

Verde: con antecedente de alcoholismo

Azul: sin antecedente de alcoholismo 